\title{
Oxidative Stability of Fats and Oils Measured by Differential Scanning Calorimetry for Food and Industrial Applications
}

\author{
M.D.A. Saldaña and S.I. Martínez-Monteagudo
}

Additional information is available at the end of the chapter

http://dx.doi.org/10.5772/54486

\section{Introduction}

Fats and oils are important ingredients in the human diet for nutritional and sensory contributions. The terms fats and oils commonly refer to their phase being solid and liquid, respectively. In addition, lipids are the main ingredients to manufacture various products, such as soups, butter, ready to eat food, among others for the food industry and other products, such as lipstick, creams, etc, for the cosmetic and pharmaceutical industries. Most of these products use vegetable oils from seeds, beans, and nuts, which are important due to their high content in polyunsaturated fatty acids compared to animal fats. However, oxidation of unsaturated fatty acids is the main reaction responsible for the lipid degradation, which is related to the final quality of the product. Furthermore, lipids undergo oxidation, developing unpleasant taste, off flavour and undesirable changes in quality, decreasing the nutritional value of the product and compromising safety of the product that might even affect health and well-being.

In general, oxygen reacts with the double bonds present in lipids, following a free radical mechanism, known as autooxidation. This reaction is quite complex and depends on the lipid type used and the processing conditions. The use of thermal processes, such as frying, sterilization, hydrolysis, etc, accelerate the oxidation of lipids. Various different reactions during lipid oxidation occur simultaneously at different rates. These reactions release heat that can be measured using differential scanning calorimetry (DSC).

Oxidation temperatures and kinetic parameters obtained from DSC can be used to rank and classify lipids in terms of their oxidative stability. Therefore, the reproducibility of oxidation experiments is crucial to evaluate the oxidative stability of lipids using DSC since variables, such as pre-treatment and amount of sample, the heating protocol, among others, strongly 
influence the results. Other methods that assess the extent of oxidative deterioration are peroxide value (PV) that measures volumetrically the concentration of hydroperoxides, anisidine value $(\mathrm{AV})$, spectrophotometric measurements in the $\mathrm{UV}$ region and gas chromatography (GC) analysis for volatile compounds [1-3]. Over the years, thousands of studies have focused on monitoring and evaluating the oxidation of lipids using the Rancimat method, PV, AV, spectrophotometric and GC analysis of fats and oils from various sources. However, it is beyond the scope of this chapter to provide a comprehensive listing of all research using those methods. Comprehensive reviews on the oxidative lipid deterioration using those methods are well discussed somewhere else [4-6].

Among all these methods that measure the extent of lipid oxidation, DSC is widely used as an analytical, diagnostic and research tool from which relevant information, such as onset temperature of oxidation ( $\mathrm{T}_{\mathrm{on}}$ ), height, shape and position of peaks are obtained and used for subsequent kinetic calculations. Kinetic information of lipid oxidation has been reported for a number of lipid systems, such as soybean/anhydrous milk fat blends, unsaturated fatty acids (oleic, linoleic, and linolenic acids), saturated fatty acids (lauric, myristic, palmitic, and stearic acids), "natural" vegetable oils (canola, corn, cottonseed, and soybean oils) and genetically modified vegetable oils.

This chapter focuses on the principles of lipid oxidation, the use of DSC technique to evaluate lipid oxidation, and recent studies on oxidative stability of fats and oils for food and industrial applications, addressing the generation and analysis of DSC thermograms for kinetic studies, where a method to analyse DSC data is described in detail, as well as the interpretation of kinetic parameters obtained at isothermal and non-isothermal conditions. In addition, some results on oxidation kinetics of milk fat after the use of traditional and emerging technologies, such as enzymatic hydrolysis and pressure assisted thermal processing are discussed in detail. Finally, conclusions on lipid oxidation analysis by DSC are provided.

\section{Fundamentals of lipid oxidation}

Lipid oxidation is a free radical chain reaction that leads to the development of unpleasant flavour and taste, loss of nutrients and formation of toxic compounds [7, 8]. Consequently, the shelf life and the final use of any lipid depend on its resistance to oxidation or oxidative stability [9]. The term lipid oxidation usually refers to a three consecutive reactions or stages, known as initiation, propagation and termination (Figure 1). In the initiation stage, free radicals are formed through thermolysis, where the break of covalent bonds is induced by heat. In addition, free radicals can also be formed due to the presence of enzymes, light, metal ions $\left(\mathrm{Ca}^{2+}\right.$ and $\left.\mathrm{Fe}^{3+}\right)$ and reactive oxygen species. A list of initiators of lipid oxidation and their standard reduction potentials are provided somewhere else [10]. Compounds that homolyze at relative low temperature $\left(<100^{\circ} \mathrm{C}\right)$ are important initiators of radical-based chain reactions. Unsaturated fatty acids are compounds that homolyze at lower temperatures compare to saturated fatty acids. The homolytic products of unsaturated fatty acids are hydroxyl radical $\left(\mathrm{HO}^{*}\right)$, alkyl radical $\left(\mathrm{RO}^{*}\right)$ and hydroperoxyl radical $\left(\mathrm{HOO}^{*}\right)$, 
which further reacts with triplet oxygen to form peroxyl radicals. Among the starters, hydroxyl radicals are mainly responsible for the initiation of lipid oxidation due to its strong tendency to acquire electrons [10]. These radical products that have high energy, bond to a hydrogen molecule from the lipid structure, forming hydroperoxides (primary oxidation products). The formation of hydroperoxides can be repeated several times, propagating the oxidation reactions. Conjugated fatty acids have more than one type of primary oxidation products and more than one oxidation pathway, as previously reported [11, 12]. A kinetic analysis on autoxidation of methyl-conjugated linoleate showed that monomeric and cyclic peroxides are the major primary oxidation products rather than hydroperoxides [12]. Consequently, addition by Diels Alder-type reaction was earlier suggested as a reaction mechanism.

The next oxidation stage is the propagation, which consists in the further degradation of hydroperoxides or any other primary oxidation product [1]. There are mainly two types of degradation products from hydroperoxides. First, hydroperoxides interact with double bonds to form monomeric degradation products, such as ketones. The reaction occurs through the reduction of the hydroperoxyl group to hydroxyl derivative. Second, low molecular weight products, that results from the cleavage of the hydroperoxide chain, form aldehydes, ketones, alcohols and hydrocarbons. These low molecular weight compounds are responsible for the rancid and off-flavour produced by oxidized fats [1-4]. Finally, hydroperoxides and primary oxidation products homolyze to form peroxyl or alkoxy radicals that further reacts to form stable dimer-like products. In addition, alcohols, and unsaturated fatty acids (secondary oxidation products) also lead to termination products. The resulting compounds form viscous materials through polymerization as the oxidation proceeds. These polymers are oil insoluble and represent the termination stage of oxidation $[2,15]$.

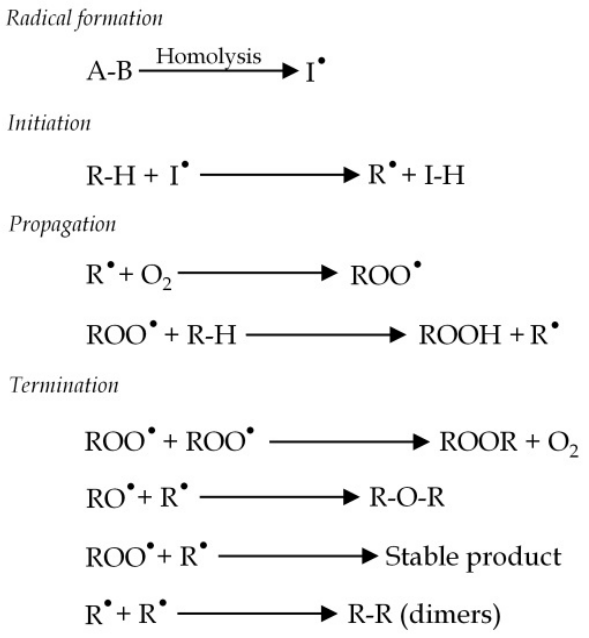

Figure 1. Main lipid oxidation reactions. 


\section{Fundamentals on the use of DSC to study lipid oxidation}

The oxidation mechanisms presented in Figure 1 is an oversimplification because lipids consist of a non-homogeneous mixture of fatty acids. For example, anhydrous milk fat (AMF) is composed of more than 400 fatty acids with extremely diverse chain lengths, position and number of unsaturations of their fatty acids [13, 14]. Consequently, several reactions occur simultaneously at different rates as the oxidation proceeds. Although several methods have been used to analyze and monitor lipid oxidation [1], the oxidation reactions cannot be measured by a single method due to their complexity. Some of the available methods allow quantifying one or more reaction products of the different oxidation stages. Methods, such as oxidative stability index (OSI) and peroxide value (PV) are officially accepted by the American of Analytical Communities (AOAC) [1-6], while other methods are routinely used, such as the Racimat, chemilominescent, and volumetric methods [16].

An important overlooked characteristic of the oxidation reactions of lipids is the exothermal effect as the oxidation occurs. The released heat from a particular reaction can be measured using DSC in either isothermal or non-isothermal mode. For DSC oxidation measurements, the heat released from the oxidized oil is compared to the heat flowing from an inert reference (empty pan) both heated at the same rate. When the oxidation of the sample occurs, the recorded heat shows a peak which area is proportional to the amount of heat released by the sample. Figure 2 shows an ideal thermogram for the non-isothermal oil oxidation with the three consecutive reaction stages of initiation, propagation and termination.

The heat released by the oxidized oil is recorded as the heat flow signal ( $y$-axis) as a function of temperature ( $x$-axis). The period of time where no change in the heat flow signal occurs is known as the induction time (Figure 2) that is exemplified at the beginning of the thermogram. An excellent review on the theory and application of induction time is provided elsewhere [17]. The length of the induction time is often considered as a measurement of oil stability. During this period, no chemical reaction occurs. At the point in

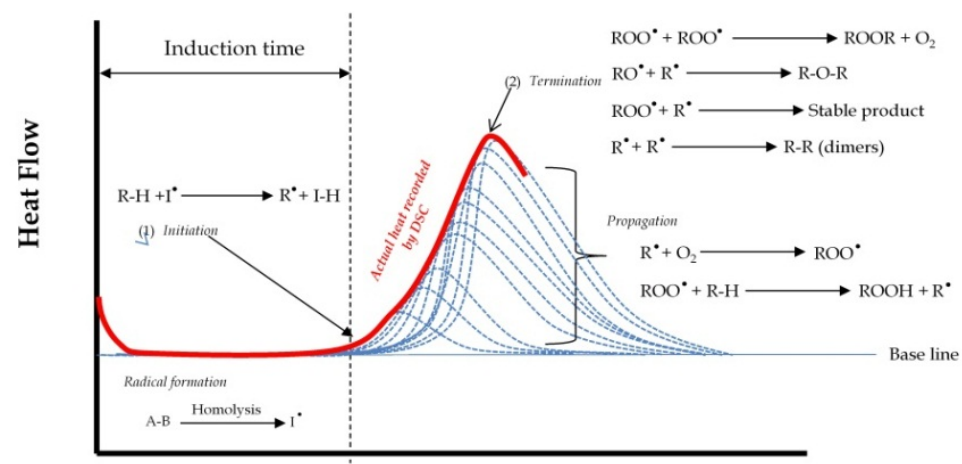

Temperature

Figure 2. Ideal thermogram of non-isothermal oil oxidation. 
which the heat flow signal separates from the baseline (straight line) is considered to be the end of the induction time (arrow (1)). Arrow (1) also indicates the start of oxidation or initiation stage. This stage is short and can be theoretically interpreted as the reaction between the radical, formed during the induction time, and the unsaturated fatty acid. The products of this reaction are unstable hydroperoxides that further react propagating the oxidation. A sudden increase in the heat flow signal is related to the propagation stage. The blue dashed lines illustrate oxidation reactions that occur and cannot be detected by the DSC because they are less exothermal. Finally, arrow (2) illustrates the termination stage, where stable products are formed. The red line is the actual heat flow recorded by the DSC.

In the next section, a set of recommended guidelines and laboratory practices are reviewed for the good use and analysis of data using DSC.

\section{Important considerations for measurement of lipid oxidation using DSC}

Although DSC is a simple, convenient and fast technique to measure lipid oxidation, some recommended guidelines should be considered to obtain reliable and reproducible results. Among those guidelines are the pre-treatment and sample preparation, amount of sample used, heating protocol, gas flow rate, and interpretation of DSC thermograms.

Sample pre-treatment - a representative amount of lipid sample should be used for DSC oxidation measurements. The lipid should be melted at a temperature that ensures that its thermal memory is erased. The melting temperature for lipids is quite diverse, ranging from -25 to $80^{\circ} \mathrm{C}$. Melting temperatures of some vegetable oils are provided elsewhere [18]. In some lipid-based products, the pre-treatment of sample involves the fat extraction from the food matrix. For example, fat from commercial baby formulas was first extracted with chloroform [19], and then the fat was further dried under vacuum. Therefore, the behavior of these extracted fats might be different from the fat in the original matrix. In addition, a proper chemical description of any pre-treatment must be provided together with the thermal history.

Sample preparation - a liquid sample should be loaded into the DSC pan using a syringe or a Pasteur pipette. The lipid oxidation measured by DSC can be conducted in an open aluminum pan or in a hermetic sealed pan with a pinhole (Figure 3). The main difference between an open pan and a sealed pan with a pinhole is the diffusion of oxygen and the amount of oxygen that is in contact with the sample. This is because the thermal conductivity of the air is smaller than that of the metal of the pan. Indeed, numerical simulations showed that the energy transmitted to the sample comes from the plate, which transmits the heat to the pan [20].

A comparison of glycerol oxidation obtained in an open pan and a hermetic sealed pan with a pinhole was earlier reported [21]. For experiments conducted in an open pan, the maximum heat flow temperature of oxidation of glycerol was around $40^{\circ} \mathrm{C}$ lower than those obtained with sealed pans. In an open pan, the vapor produced during lipid oxidation 


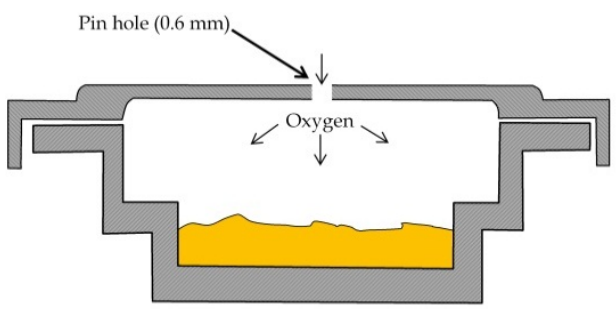

(a)

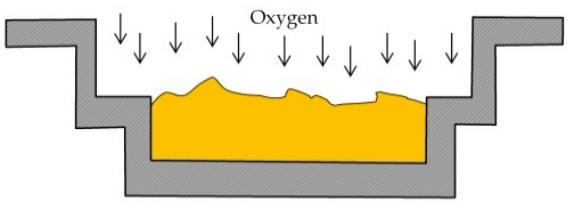

(b)

Figure 3. Illustrations of common DSC pans: (a) hermetically sealed pan with a pinhole, and (b) an open aluminium pan.

leaves the pan as it is formed. This is because the purge of oxygen acts as a carrier of the vapor. Consequently, part of the mass is lost before reaching the temperature at which the oxidation starts. On the other hand, in a sealed pan with a pinhole, the vapor produced cannot escape from the pan, remaining in the oil. This vapor increases the pressure inside the pan and elevates the oxidation temperature. Contradictory results were reported for the melting temperature of benzoic acid and vanillin obtained in an open pan and a sealed pan with a pinhole [22]. No significant differences were observed in the onset temperature ( $\left.T_{\text {on }}\right)$ and the peak maximum temperature $\left(\mathrm{T}_{\mathrm{p}}\right)$. Unfortunately, studies with a direct comparison between the types of pans (open and sealed with a pinhole) for oxidation of are scarce in the literature. Indeed, the international organization for standardization does not specify the types of pans for the determination of oxidation induction time [23]. Although hermetic sealed pans with a pinhole have an additional cost to each experimental run, their use avoids contamination of the DSC chamber.

Sample size - the amount of sample has significant effect on the shape of the thermogram and reproducibility of the DSC oxidation experiments as it is related to heat transfer within the pan. Figure 4 illustrates the effect of the amount of sample in hermetic sealed pans with a pinhole. For the sample with an optimum sample thickness (Figure 4a), the oil is in contact with excess of oxygen, facilitating oxygen diffusion within the oil sample. An earlier study [7] recommended $1 \mathrm{~mm}$ of sample thickness (approximately $1.5 \mathrm{mg}$ of oil) to yield consistent results in non-isothermal oil oxidation. Similarly, no changes on the DSC thermograms using samples between 1 to $4 \mathrm{mg}$ were reported [24]. A ratio of 1:3 (oil:oxygen) not only avoids diffusional limitations [6, 7, 25] but also allows the vapor molecules formed during the oxidation reaction to rapidly escape from the pan [26]. This enhances the baseline and the resolution of the oxidation thermogram [27].

On the other hand, an excess of sample (Figure $4 \mathrm{~b}$ ) creates a temperature gradient within the sample, especially at high heating rates [27]. Also, the diffusion of oxygen is limited, which broader the DSC oxidation curves. This is illustrated in Figure 5 where samples of 3 and 13 $\mathrm{mg}$ of anhydrous milk fat (AMF) were oxidized at $12^{\circ} \mathrm{C} / \mathrm{min}$ from 100 to $250^{\circ} \mathrm{C}$. Interestingly, the $\mathrm{T}_{\text {on }}$ of oxidation is quite similar between samples $\left(181.12\right.$ and $179.33^{\circ} \mathrm{C}$, respectively). But, the use of $13 \mathrm{mg}$ of AMF leads to a broader and less resolved curve. The deviation of the heat flow signal from the vertical edge (broadening) is attributed to a longer time needed to 
oxidize a larger sample and the development of a temperature gradient within the sample. Another reason is that the probability of vapor molecules to escape from the pan through the pinhole is considerable reduced. Consequently, the peak maximum temperature shifts to a lower temperature because some of the vapor molecules react, accelerating the termination stage of oxidation.

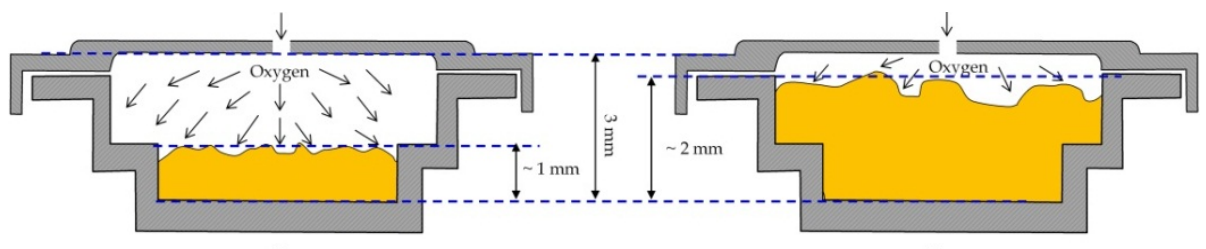

(a)

(b)

Figure 4. Illustration of (a) optimum sample size, and (b) excess sample size, in hermetic sealed pans with a pinhole.

Heating rate - this is one of the most important parameters to determine the oxidative stability and oxidation kinetics of lipids. Before the start of the heating rate, an equilibrium period between 3 and $5 \mathrm{~min}$ is recommended to enhance the baseline. At slow heating rates, primary oxidation products, such as hydroperoxides generated during the initial oxidation stage, react with excess of oxygen to form low molecular weight compounds (intermediate oxidation products), accelerating the degradation process. At fast heating rates, these intermediate products are lost through evaporation before they react with the lipid, shifting to a high value the threshold DSC signal $[6,9]$. This phenomenon is the basis to calculate the kinetic parameters from a DSC thermogram [28]. However, it is important to highlight that the heating rate should not exceed $25^{\circ} \mathrm{C} / \mathrm{min}$ since the temperature of the sample is different from the furnace temperature, creating a temperature gradient which affects the oxidation kinetics [29]. An important overlooked consideration is the temperature range at which the oxidation study should be conducted. In general, the temperature range should start and end as far as possible from the $T_{\text {on }}$ and $T_{p}$ (approximately a difference of at least $50^{\circ} \mathrm{C}$ ).

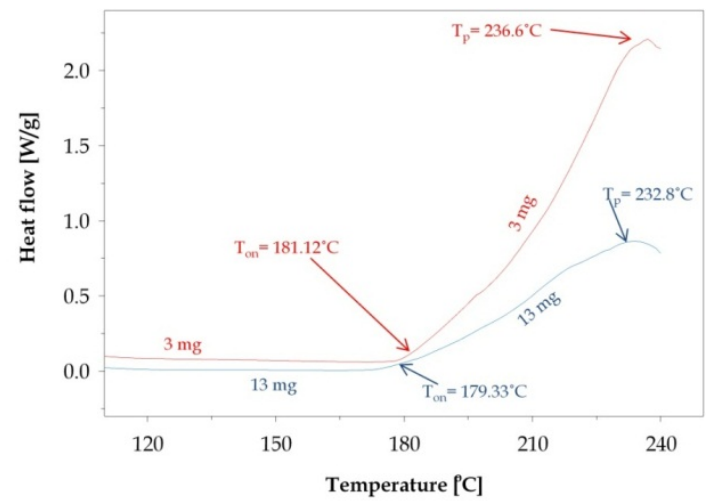

Figure 5. Effect of sample size on non-isothermal oxidation of anhydrous milk fat at $12^{\circ} \mathrm{C} / \mathrm{min}$. $\mathrm{T}_{\mathrm{on}}$ - onset temperature of oxidation; $\mathrm{T}_{\mathrm{p}}$ - maximum heat flow temperature. 
DSC mode - oxidation experiments can be conducted in either isothermal or non-isothermal mode. Both methods provide analytical information, such as the oxidation induction time in the case of isothermal measurements and the oxidation onset temperature in the case of nonisothermal measurements [28, 29]. Further comparisons on the kinetic studies conducted in either isothermal or non-isothermal mode are discussed in the following sections.

\section{Analysis of DSC thermograms}

\subsection{Location of key parameters}

The analysis and interpretation of the generated DSC spectra consist in identifying key parameters, such as the induction time, onset and peak maximum temperatures. These key parameters are manually obtained from the DSC spectra. The $T_{\text {on }}$ is obtained extrapolating the tangent drawn on the steepest slope of $T_{p}$. This procedure is usually performed

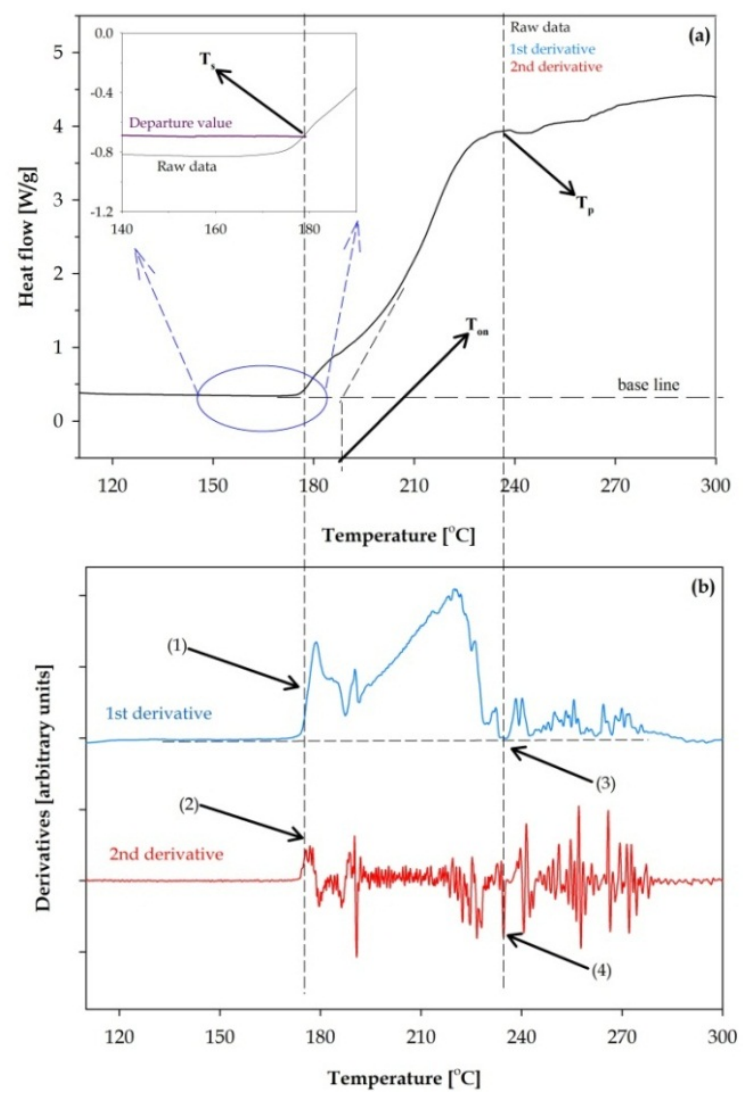

Figure 6. Anhydrous milk fat rich in conjugated linoleic acid oxidized at $15^{\circ} \mathrm{C} \mathrm{min}-1$. (a) Determination of the start temperature $\left(\mathrm{T}_{\mathrm{s}}\right)$ (inlet), onset temperature $\left(\mathrm{T}_{\mathrm{on}}\right)$ and maximum heat flow temperature $\left(\mathrm{T}_{\mathrm{p}}\right)$, and (b) zoom on the first and second derivatives that precisely locates the $\mathrm{T}_{\mathrm{s}}, \mathrm{T}_{\mathrm{on}}$, and $\mathrm{T}_{\mathrm{p}}$ 
manually by the DSC operator, relying in the equipment software. Inherently, there is certain degree of uncertainty associated with this procedure. A method that accurately and unambiguously determines those key parameters from the DSC spectra was early proposed for lipid crystallization [30]. This method was first developed to calculate onset, offset, and peak maximum temperatures in crystallization of binary mixtures of different triacylglycerols. More recently, the same methodology was adapted to calculate the start, onset and peak maximum temperatures in non-isothermal oxidation of anhydrous milk fat [9]. Figure 6 exemplifies the location of the start, onset and peak maximum temperatures for anhydrous milk fat rich in conjugated linoleic acid oxidized at $15^{\circ} \mathrm{C} / \mathrm{min}$ in a hermetic sealed pan with a pinhole.

Once the DSC curves are generated, the error associated with the raw data is calculated through standard deviation. Then, the first and second derivatives are calculated. The error is obtained from the baseline, which in Figure 6 corresponds to the segment of 140 to $178^{\circ} \mathrm{C}$. This is essential since the signal variability can be misinterpreted as a thermal event. In this method, a true thermal event was considered when the heat flow signal is twice greater than the standard deviation of the baseline. This criterion is known as the departure value (inlet Figure 6a). To locate the start temperature of oxidation, three criteria were considered. Firstly, the first derivative of the signal shows an inflexion point between a maximum and a minimum point of the signal (arrow (1)). Secondly, the second derivative reaches a maximum point on the heat flow signal (arrow (2)). Finally, the heat flow signal should be greater than the departure value (inlet). $T_{p}$ was obtained when the first derivative of the signal intersects with the $x$-axis (arrow (3)) and the second derivative reached a maximum point on the signal (arrow (4)). Ton was obtained extrapolating the tangent drawn on the steepest slope of $\mathrm{T}_{\mathrm{p}}$.

\subsection{Iso-conversional method}

In chemical reactions, the degree of conversion $(0 \leq \alpha \leq 1)$ or extent of reaction of a particular compound is defined by moles at a given time divided by the initial moles [29]. Similarly, $\alpha$ in thermal analysis is defined by the heat flow at a given time or temperature divided by the heat flow at time or temperature at which the maximum heat flow signal is reached. The heat flow from the DSC spectra is converted to $\alpha$ based on the initial (signalo) and final (signalf) heat flow signals, as shown in equation (1).

$$
\alpha=\frac{\text { signal }_{o}-\text { signal }}{\text { signal }_{o}-\text { signal }_{f}}
$$

At a given degree of conversion, the reaction kinetics is described by a single-step reaction that follows an Arrhenius type equation within a narrow range of temperature. Then, the overall kinetics [31-34] is the result of multiple single-step reactions in the form:

$$
\frac{d \alpha}{d t}=A \exp { }^{\left(\frac{-E_{a}}{R T}\right)} f(\alpha)
$$


where $t$ is the time, $A$ is the pre-exponential factor, $E_{a}$ is the effective activation energy, $T$ is the temperature, and $f(\alpha)$ is the reaction model. This procedure, known as iso-conversional or model-free method, is used to calculate kinetic triplet parameters (effective activation energy, $E a$, pre-exponential factor, $A$ and constant rate, $k$ ) in thermally stimulated reactions [29-34]. As known, reactions are the sequence of physical changes that can be measured by thermal techniques.

In non-isothermal oxidation of lipids, the consumption of oxygen can be neglected due to the large excess of oxygen generated by a constant flow rate ( $>25 \mathrm{~mL} / \mathrm{min})$. Such condition allows the formation of peroxides, being independently of the oxygen concentration, which also means that the autoxidation is a first order reaction [7, 9]. This is an essential assumption for the calculation of the kinetic triplet parameters $\left(E_{a}, A\right.$, and $k$ ). A commonly used iso-conversional method is the Ozawa-Flynn-Wall method. Using this method, a set of data $\left(T_{s}, T_{o n}\right.$, and $\left.T_{p}\right)$ was obtained for constant heating rates $(\beta=d T / d t)$ from which the kinetic parameters were calculated using the following equations:

$$
\log \beta=a \frac{1}{T}+b
$$

where $\beta$ is the heating rate $(\mathrm{K} / \mathrm{min})$ and $T$ is the temperature $T_{s}, T_{o n}$, or $T_{p}(\mathrm{~K})$. By plotting log $\beta$ against $1 / T$, the effective activation energy $\left(E_{a}\right)$ and the pre-exponential factor $(A)$ were determined directly from the slope and intercept according to:

$$
\begin{gathered}
a=-0.4567 \frac{E_{a}}{R} \\
b=-2.315+\log \left(A \frac{E_{a}}{T}\right)
\end{gathered}
$$

where $a$ and $b$ are the slope and intercept from equation (3), respectively, and $R$ is the universal gas constant $(8.31 \mathrm{~J} / \mathrm{mol} \mathrm{K})$. Therefore, the effective activation energy $\left(E_{a}\right)$ and the constant rate $(k)$ are calculated from:

$$
\begin{gathered}
E_{a}=-2.19 R \frac{d \log \beta}{d T^{-1}} \\
k=A \exp \\
\left(\frac{E_{a}}{R T}\right)
\end{gathered}
$$

\subsection{Induction time}

As mentioned earlier, the period of time where no change in the heat flow signal occurs is known as the induction time and its length is considered as a measurement of lipid stability [17]. The determination of the induction period is routinely conducted to evaluate stability of oils, lubricants, biodiesel, and pharmaceutical products [34-38]. Unfortunately, no 
standard protocol for the determination of the oxidation induction time has been developed for lipids.

Figure 7a illustrates the standard protocol for determination of oxidation induction time (OIT). The polymer sample (15 mg) is rapidly heated under nitrogen atmosphere ( $\leq$ $20^{\circ} \mathrm{C} / \mathrm{min}$ ) until it reaches the temperature that corresponds to time, $\mathrm{t}_{1}$, which is the starting point for OIT determination. At $t_{1}$, the atmosphere is switched to oxygen and the sample is held at the same temperature until $t_{2}$ is reached. The difference between $t_{2}$ and $t_{1}$ is the OIT. A disadvantage of this protocol is to find an adequate temperature for the isothermal stage. For example, the use of a low temperature might considerably increase the OIT while the use of a high temperature might oxidize the sample immediately, making difficult to obtain a reliable baseline. In tests conducted in 16 different laboratories, it was demonstrated that OIT is associated with a high degree of uncertainty. On the other hand, Figure $7 \mathrm{~b}$ illustrates the experimental protocol for the determination of oxidation induction temperature (OIT ${ }^{*}$ ). In this case, the sample is continuously heated at a constant heat rate (for example, $12^{\circ} \mathrm{C} / \mathrm{min}$ ) under oxygen atmosphere.
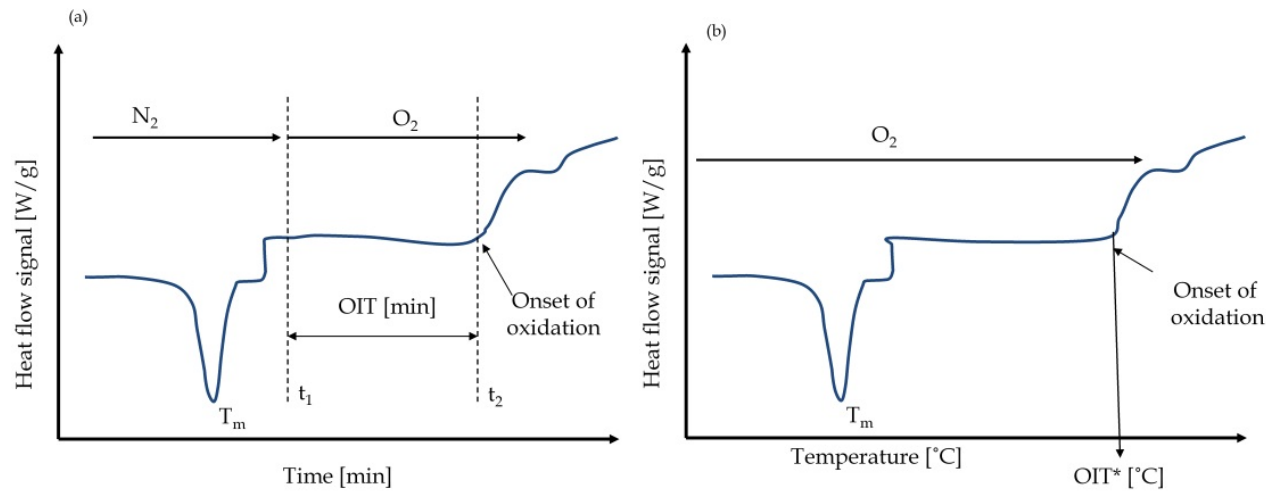

Figure 7. Determination of oxidation induction time, OIT (a), and oxidation induction temperature, $\mathrm{OIT}^{*}(\mathrm{~b})$. $\mathrm{T}_{\mathrm{m}}$ - melting temperature, $\mathrm{t}_{1}$ - start of the oxidation induction time, $\mathrm{t}_{2}$ - end of the oxidation induction time. Adapted from reference [35].

\section{Kinetic studies of oxidation of fats and oils}

Tables 1 and 2 summarize oxidation studies of fats and oils using DSC. Most of the isothermal studies were conducted between 80 and $180^{\circ} \mathrm{C}$ with different flow rates varying from 10 to $100 \mathrm{~mL} / \mathrm{min}$. The amount of sample used also varied from 3 to $30 \mathrm{mg}$ and most of these studies used open pans. The oxidation onset times were quite diverse (23-108 $\mathrm{min}$ ) and therefore the $E_{a}$ values ranged from 50 to $130 \mathrm{~kJ} / \mathrm{mol}$, depending mainly on the oil composition, temperature, and amount of sample. For the non-isothermal studies, the temperature ranged from 50 to $350^{\circ} \mathrm{C}$ and the heating rate used ranged from 1 to $25^{\circ} \mathrm{C} / \mathrm{min}$. The onset oxidation temperatures depended on the heating rate and oil composition. 


\subsection{Isothermal studies}

For isothermal oxidation, the heat flow signal generated at constant temperature is plotted against time (Fig 7a). From these curves, the start of the oxidation ( $\left.\mathrm{t}_{1}\right)$ and the end of the oxidation induction time ( $\left.\mathrm{t}_{2}\right)$ are first located and then used for analysis [39].

Table 1 summarizes the isothermal oxidation studies of fats and oils, such as peanut, safflower seed, blackcurrant seed, rice bran, cotton seed, Buriti seed, passion fruit seed, sunflower seed, soybean, linseed, canola seed, coconut, grape seed, palm seed, and sesame seed. Earlier studies on isothermal oxidation were imprecise because the baselines obtained were highly unstable, making it difficult to obtain oxidation onset times [40, 41]. However, stable baselines were currently obtained in the isothermal oxidation of linoleic, linolenic, oleic, stearic, peanut, safflower and blackcurrant seed oils [42]. These oils were heated under argon flow. After thermal equilibrium was reached, the gas flow was switched to oxygen, allowing the oxidation to start. The temperature used to conduct the oxidation test should be far below the self-ignition temperature for fats and oils $\left(\sim 350^{\circ} \mathrm{C}\right)$. Thus, the recorded thermal events are due to lipid oxidation rather than combustion. Using this approach, the obtained induction times were reproducible and highly influenced by the test temperature and sample composition. Attempting to validate the isothermal DSC oxidation, an earlier study [43] isothermally oxidized purpurea seed, rice bran and cotton seed oils using the DSC and the Rancimat methods. At each tested temperature, the DSC oxidation times were shorter than those obtained using the Rancimat method for the same oil. Despite these differences, the oxidation times were satisfactorily correlated with the Rancimat induction times. Similarly, longer induction times were obtained with the use of the Rancimat method for Buriti pulp seed oil, rubber seed oil and passion fruit seed oil [44]. In these studies, DSC rapidly reaches the threshold of the heat flow signal. This difference is attributed to the small sample used in DSC experiments, allowing a higher oil-oxygen ratio compared to the Rancimat method. Moreover, to oxidize the oil, DSC employs pure oxygen (99\% purity) while the Rancimat method uses air ( $21 \%$ of oxygen).
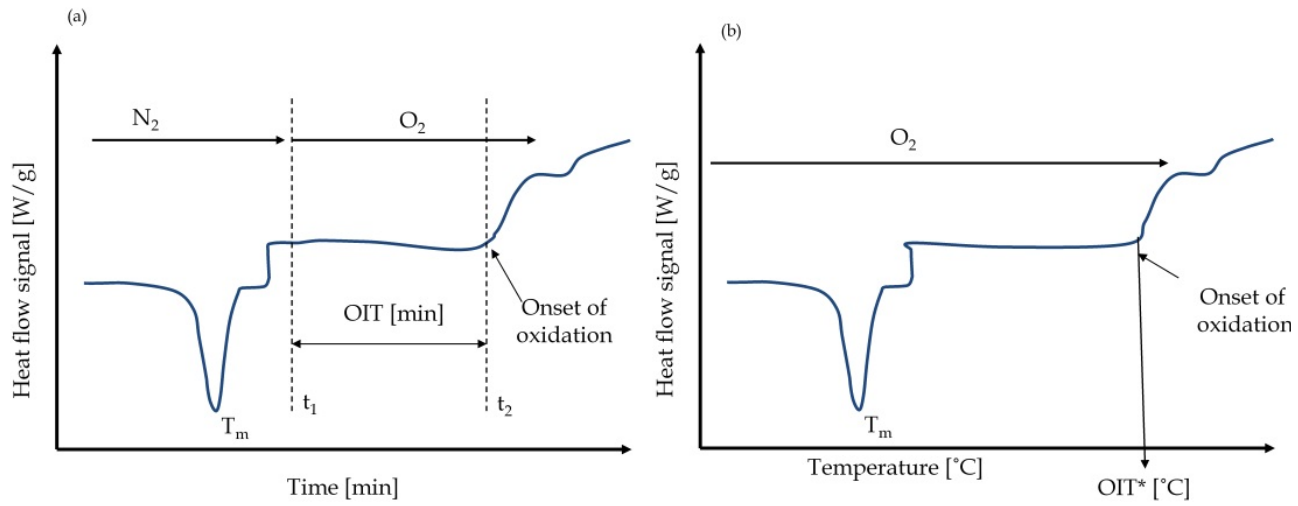
Oxidative Stability of Fats and Oils Measured by Differential Scanning Calorimetry for Food and Industrial Applications

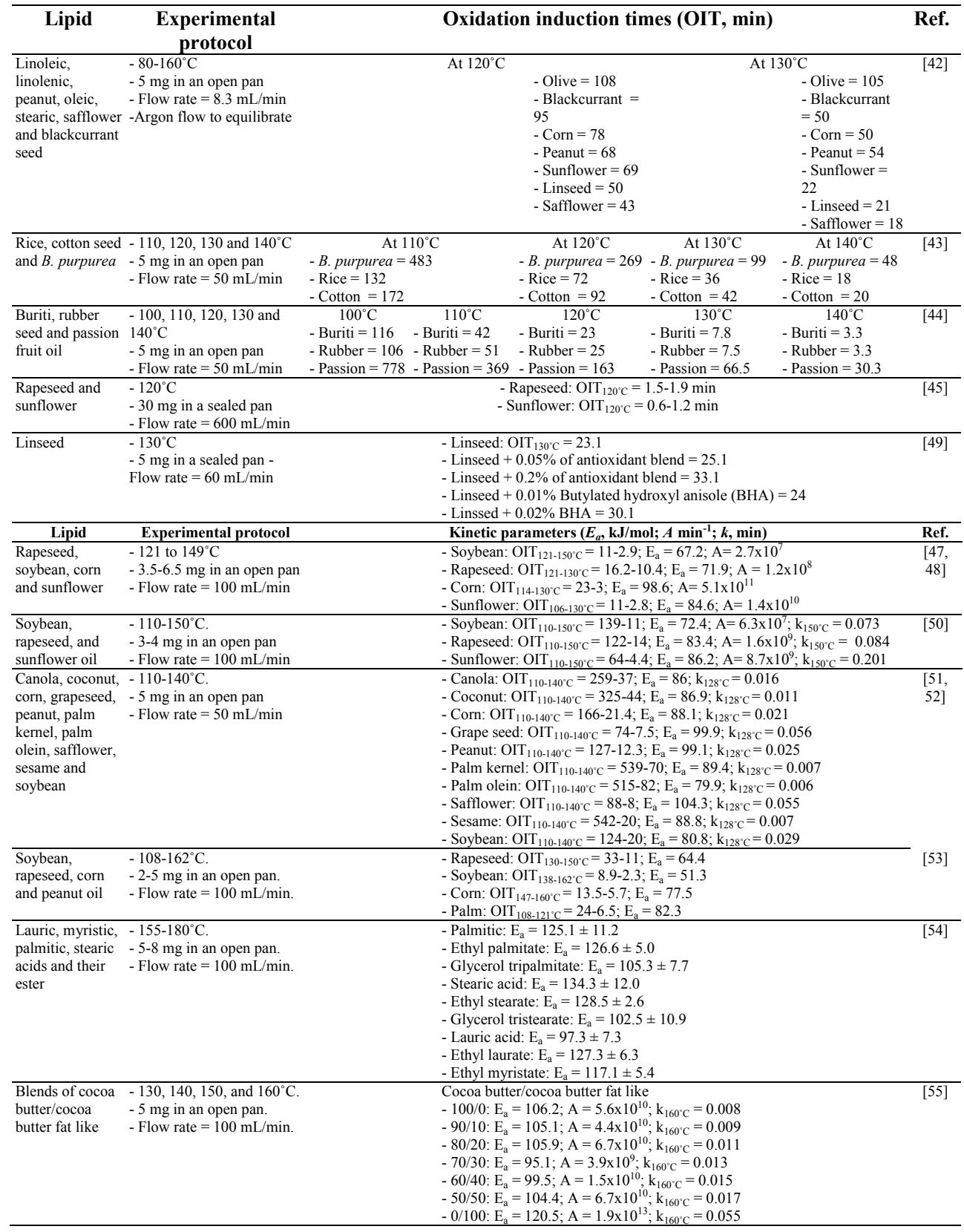

Table 1. Summary of isothermal oxidation studies of lipids using differential scanning calorimetry

A comparative study of sunflower seed oil and rapeseed oil oxidation using DSC and volatile analysis showed that the ratio of hexanal/2-trans-nonenal linearly correlates with 
the onset heat flow signal of the DSC spectra [44]. In addition, a correlation between the peroxide values with the oxidation onset time was developed to monitor rapeseed oil oxidation [44]. Unfortunately, the correlation was valid only for oils with peroxide values lower than $30 \mathrm{mmol} \mathrm{O}_{2} / \mathrm{kg}$ oil. In other study, the experimental oxidation data obtained from electron spin spectroscopy was compared with the data obtained from DSC oxidation [46]. The onset oxidation times were highly correlated for different fat and oil blends. However, the obtained correlations were valid only at moderate temperatures of $60^{\circ} \mathrm{C}$, which considerably limits the applicability of electron spin spectroscopy for oxidation analysis.

An investigation of isothermal oxidation of oils (e.g. rapeseed, soybean, corn and sunflower oils) used onset time (ton) to rank the oxidized oils in terms of their oxidative stability [47]. The high maximum heat flow time $\left(t_{p}\right)$ value indicates that the oil is more stable. Although these relationships were statistically validated, a single parameter to evaluate the oxidative stability can lead to overestimation of the oxidative stability. In the same study, the authors considered $t_{p}$ to be proportional to the rate of oxidation, which might not be valid. Indeed, peroxide value determinations showed that $t_{p}$ represents the oxidation termination stage while $t_{n}$ is associated with the rate of initiation [48]. Furthermore, the addition of antioxidants prolongs only ton while $t_{p}$ values were minimally affected [48]. The same behavior was also observed in the isothermal oxidation of linseed oil with the use of antioxidants [49]. The addition of BHA (butylated hydroxyl anisole) and a mixture of antioxidants (tocopherol, ascorbyl palmitate, citric acid and ascorbic acid) prolonged the onset time at $130^{\circ} \mathrm{C}$. All these approaches provided information of great value for validation of the DSC isothermal oxidation. However, these equations are limited for a set of temperatures and specific oils (Table 1). Additional factors, such as degree of saturation, amount of free fatty acids, chain length and the presence of natural antioxidants were not considered.

Using the isothermal method, the sample is heated at a constant temperature and the released heat is recorded as a function of temperature. Such situation allows the identification of the maximum heat flow time $\left(t_{m}\right)$, which linearly correlates with the temperature $[39,48,49]$.

$$
\log t_{m}=A \cdot T^{-1}+B
$$

where $\mathrm{A}$ and $\mathrm{B}$ are regression parameters. Due to the excess of oxygen generated by a constant flow rate, the formation of peroxides is considered to be independent of the oxygen concentration, which also means that the autoxidation is a first order reaction [48, 49]. This is an essential assumption for the calculation of kinetic parameters, such as effective activation energy $\left(E_{a}\right)$, pre-exponential factor $(A)$, and reaction rate $(k)$.

$$
E_{a}=2.19 \cdot R \cdot \frac{d \log \left(t_{m}\right)}{d T^{-1}}
$$

Equations 8 and 9 have been applied not only to obtain the maximum heat flow signal [4749] but also to obtain the oxidation onset time. An attempt to correlate induction times and 
kinetic parameters of isothermally heated rapeseed, soybean and sunflower seed oils at different temperatures was proposed [50]. The authors correlated the oxidation induction times with the tested temperature using Arrhenius-like equations. The obtained kinetic parameters were comparable to those obtained by the Rancimat method. The onset time values of 12 different oils obtained by DSC were reduced by half of their previous values for every increase of $10^{\circ} \mathrm{C}$ in the oxidation temperature [51]. These relationships were further used to obtain kinetic parameters of DSC oxidation [52]. The $E_{a}$ values of rapeseed, soybean, corn and peanut oils were strongly influenced by the amount of saturated fatty acids [53]. The oxidation of saturated fatty acids $\left(\mathrm{C}_{12}-\mathrm{C}_{18}\right)$ and their esters revealed that the Ea values $(100-125 \mathrm{~kJ} / \mathrm{mol})$ were within the same range for all the tested oils [54]. This suggests that the isothermal oxidation is not influenced by the carbon chain length. Another important conclusion from this investigation [54] is that the start of oxidation is similar for fatty acids, their esters and triglycerides. The kinetic oxidation parameters of cocoa butter blends were obtained using the oxidation onset time [55]. The blends were oxidized from 130 to $160^{\circ} \mathrm{C}$ in an open pan. Interestingly, the $E_{a}$ and $A$ values were slightly affected by the addition of saturated fatty acids. But, $k$ values considerably changed with the amount of saturated fatty acids. Thus, $k$ values can be used to rank the oxidative stability of cocoa butter blends. However, the use of $k$ values to evaluate oxidative stability might be valid only at the temperature tested since changes in the reaction mechanisms can occur as a function of temperature.

\subsection{Non-isothermal studies}

For non-isothermal oxidation studies, two maximum heat flow peaks are commonly observed in the DSC spectra [56-59]. But, only the first peak is related to lipid oxidation. This was demonstrated in non-isothermal oxidation studies of corn and linseed oils with different peroxide values [57]. A decrease in the onset temperature was observed as the peroxide value increased. Contrary, the first and second peak temperatures were not affected by increasing the peroxide value. Consequently, the first peak can be related to hydroperoxides formation while the second peak can be due to further oxidation of peroxides. In an earlier study [58], the weight loss of lecithin during non-isothermal heating under nitrogen flow rate was analyzed. The thermogravimetric analysis showed that in the temperature range of the first peak only $4 \%$ of weight was lost but above that temperature, the weight loss considerably increased. Therefore, changes in the DSC signal within the range of the first peak temperature were attributed to oxidation and those changes above that temperature corresponded to thermal degradation rather than oxidation (Figure 8).

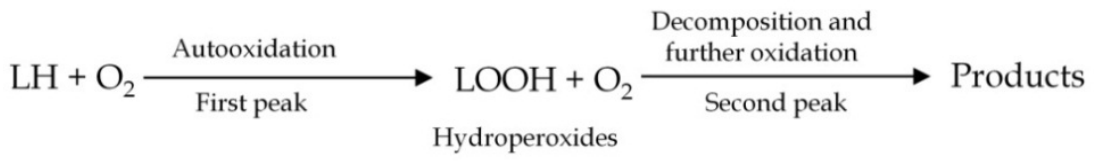

Figure 8. Reaction mechanism proposed for lipid oxidation under non-isothermal conditions. 
The proposed reactions in Figure 8 resemble to an autocatalytic reaction scheme. Indeed, computer simulated DSC oxidation curves using autocatalytic scheme fitted well the experimental data [56]. Similarly, the non-isothermal oxidation of mustard oil was best described by an autocatalytic reaction scheme [58]. Therefore, it was proposed that $T_{\text {on }}$ is the most representative reference point of lipid oxidation under non-isothermal conditions. In addition, kinetic parameters calculated from $T_{\text {on }}$ were comparable to those obtained at isothermal DSC conditions (Tables 1 and 2) [56-59]. Similarly, non-isothermal kinetics was used to evaluate the oxidative stability of commercial olive oil samples [59-62]. The obtained kinetic parameters were comparable to those obtained with the Rancimat method.

\begin{tabular}{|c|c|c|c|}
\hline Lipid & Experimental protocol & Kinetics parameters $\left(E_{a}, \mathrm{~kJ} / \mathrm{mol} ; A \min ^{-1} ; k, \min \right)$ & Ref. \\
\hline Corn and linseed oil & $\begin{array}{l}-50-300^{\circ} \mathrm{C} \\
-5 \mathrm{mg} \text { in an open pan } \\
-\beta=5-20^{\circ} \mathrm{C} / \mathrm{min} \\
\text { - Flow rate }=166 \mathrm{~mL} / \mathrm{min}\end{array}$ & $\begin{array}{l}\text { - Corn: } \mathrm{E}_{\mathrm{a}}=69.5 \pm 9.7 ; \mathrm{A}=1.25 \times 10^{8} \\
\text { - Linseed: } \mathrm{E}_{\mathrm{a}}=132.7 \pm 8.8 ; \mathrm{A}=1.15 \times 10^{16} \\
\text { Onset temperature } \\
\text { - Corn }+47 \mathrm{mmol} \mathrm{O}_{2} / \mathrm{kg}=146^{\circ} \mathrm{C} \\
\text { - Corn }+70 \mathrm{mmol} \mathrm{O}_{2} / \mathrm{kg}=142^{\circ} \mathrm{C} \\
\text { - Corn }+93 \mathrm{mmol} \mathrm{O}_{2} / \mathrm{kg}=137^{\circ} \mathrm{C} \\
\text { - Corn }+136 \mathrm{mmol} \mathrm{O}_{2} / \mathrm{kg}=137^{\circ} \mathrm{C} \\
\text { - Corn }+145 \mathrm{mmol} \mathrm{O}_{2} / \mathrm{kg}=128^{\circ} \mathrm{C} \\
\text { - Corn }+158 \mathrm{mmol} \mathrm{O}_{2} / \mathrm{kg}=127^{\circ} \mathrm{C} \\
\text { - Linseed }+31 \mathrm{mmol} \mathrm{O}_{2} / \mathrm{kg}=144^{\circ} \mathrm{C} \\
\text { - Linseed }+119 \mathrm{mmol} \mathrm{O}_{2} / \mathrm{kg}=131^{\circ} \mathrm{C} \\
\text { - Linseed }+180 \mathrm{mmol} \mathrm{O}_{2} / \mathrm{kg}=129^{\circ} \mathrm{C} \\
\text { - Linseed }+252 \mathrm{mmol} \mathrm{O}_{2} / \mathrm{kg}=125^{\circ} \mathrm{C} \\
\text { - Linseed }+349 \mathrm{mmol} \mathrm{O}_{2} / \mathrm{kg}=117^{\circ} \mathrm{C} \\
\text { - Linseed }+383 \mathrm{mmol} \mathrm{O}_{2} / \mathrm{kg}=121^{\circ} \mathrm{C}\end{array}$ & {$[56]$} \\
\hline Linolenic acid and soy lecithin & $\begin{array}{l}-50-300^{\circ} \mathrm{C} \\
-5 \mathrm{mg} \text { in an open pan } \\
-\beta=2-20^{\circ} \mathrm{C} / \mathrm{min} \\
\text { - Flow rate }=6600 \mathrm{~mL} / \mathrm{min}\end{array}$ & $\begin{array}{l}\text { - Linolenic: } \mathrm{E}_{\mathrm{a}} \text { from } \mathrm{T}_{\mathrm{on}}: 65 \pm 4 ; \mathrm{A}=2.3 \times 10^{7} ; \mathrm{k}_{100^{\circ} \mathrm{C}}=0.016 \\
\text { - Linolenic: } \mathrm{E}_{\mathrm{a}} \text { from } \mathrm{T}_{\mathrm{p}}: 78.9 \pm 6.9 ; \mathrm{A}=9.9 \times 10^{7} \\
\text { - Lecithin: } \mathrm{E}_{\mathrm{a}} \text { from } \mathrm{T}_{\mathrm{on}}: 97 \pm 81 ; \mathrm{A}=2.4 \times 10^{11} ; \mathrm{k}_{100^{\circ} \mathrm{C}}=0.001 \\
\text { - Linolenic: } \mathrm{E}_{\mathrm{a}} \text { from } \mathrm{T}_{\mathrm{p}}: 141.4 \pm 4 ; \mathrm{A}=9.4 \times 10^{15}\end{array}$ & {$[57]$} \\
\hline Mustartd oil & $\begin{array}{l}-140-350^{\circ} \mathrm{C} \\
-3-5 \mathrm{mg} \text { in an open pan } \\
-\beta=2,5,7.5,10 \text {, and } 15^{\circ} \mathrm{C} / \mathrm{min} \\
\text { - Flow rate }=100 \mathrm{~mL} / \mathrm{min}\end{array}$ & $\begin{array}{l}\text { - From onset: } \mathrm{E}_{\mathrm{a}}=90.6 ; \mathrm{A}=3.4 \times 10^{9} ; \mathrm{k}_{225^{\circ} \mathrm{C}}=0.97 \\
\text { - From 1st peak: } \mathrm{E}_{\mathrm{a}}=88.5 ; \mathrm{A}=1.4 \times 10^{9} ; \mathrm{k}_{225^{\circ} \mathrm{C}}=0.90 \\
\text { - From 2nd peak: } \mathrm{E}_{\mathrm{a}}=84.6 ; \mathrm{A}=4.4 \times 10^{7} ; \mathrm{k}_{225^{\circ} \mathrm{C}}=1.12\end{array}$ & $\begin{array}{l}58] \\
\end{array}$ \\
\hline Olive oil & $\begin{array}{l}\text { - } 2-3 \mathrm{mg} \text { in an open pan } \\
-\beta=4,5,7.5,10,12.5,15^{\circ} \mathrm{C} / \mathrm{min} \\
\text { - Flow rate }=100 \mathrm{~mL} / \mathrm{min}\end{array}$ & $\begin{array}{l}-\mathrm{E}_{\mathrm{a}} \text { calculated from } \mathrm{T}_{\text {on }}: 72-104 ; \mathrm{A}=3.31 \times 10^{8}-1.1 \times 10^{12} \\
\mathrm{k}_{120^{\circ} \mathrm{C}}=0.09-0.015\end{array}$ & {$[59]$} \\
\hline Blends of soybean/AMF & $\begin{array}{l}-100 \text { to } 350^{\circ} \mathrm{C} \\
-5-15 \mathrm{mg} \text { in an open pan } \\
-\beta=2.5-12.5^{\circ} \mathrm{C} / \mathrm{min} \\
\text { - Flow rate }=100 \mathrm{~mL} / \mathrm{min}\end{array}$ & $\begin{array}{l}\text { Soybean } / A M F \\
-100 / 0: \mathrm{E}_{\mathrm{a}}=93.5 ; \mathrm{A}=1.25 .6 \times 10^{10} ; \mathrm{k}_{200}{ }^{\circ} \mathrm{C}=0.57 \\
-90 / 10: \mathrm{E}_{\mathrm{a}}=59.5 ; \mathrm{A}=2.5 \times 10^{6} ; \mathrm{k}_{200^{\circ} \mathrm{C}}=0.68 \\
-80 / 20: \mathrm{E}_{\mathrm{a}}=58.4 ; \mathrm{A}=2.1 \times 10^{6} ; \mathrm{k}_{200^{\circ} \mathrm{C}}=0.71 \\
-70 / 30: \mathrm{E}_{\mathrm{a}}=64.5 ; \mathrm{A}=1.1 \times 10^{7} ; \mathrm{k}_{200^{\circ} \mathrm{C}}=0.80 \\
-60 / 40: \mathrm{E}_{\mathrm{a}}=70.2 ; \mathrm{A}=5.2 \times 10^{7} ; \mathrm{k}_{200^{\circ} \mathrm{C}}=0.88 \\
-50 / 50: \mathrm{E}_{\mathrm{a}}=73.2 ; \mathrm{A}=1.1 \times 10^{8} ; \mathrm{k}_{200^{\circ} \mathrm{C}}=0.95 \\
-40 / 60: \mathrm{E}_{\mathrm{a}}=102.7 ; \mathrm{A}=2.6 \times 10^{11} ; \mathrm{k}_{200^{\circ} \mathrm{C}}=1.18 \\
-30 / 70: \mathrm{E}_{\mathrm{a}}=102.8 ; \mathrm{A}=2.7 \times 10^{11} ; \mathrm{k}_{200^{\circ} \mathrm{C}}=1.20 \\
-20 / 80: \mathrm{E}_{\mathrm{a}}=105.8 ; \mathrm{A}=5.3 \times 10^{11} ; \mathrm{k}_{200^{\circ} \mathrm{C}}=1.26 \\
-10 / 90: \mathrm{E}_{\mathrm{a}}=117.4 ; \mathrm{A}=1.4 \times 10^{13} ; \mathrm{k}_{200^{\circ} \mathrm{C}}=1.55 \\
-0 / 100: \mathrm{E}_{\mathrm{a}}=89.5 ; \mathrm{A}=8.4 \times 10^{9} ; \mathrm{k}_{200^{\circ} \mathrm{C}}=1.09\end{array}$ & {$[62]$} \\
\hline $\begin{array}{l}\text { Oleic, erucic, linoleic, linolenic } \\
\text { and their ethyl esters and } \\
\text { glycerol trioleate and trilinoleate }\end{array}$ & $\begin{array}{l}\text { - Temperature }=50-300^{\circ} \mathrm{C} \\
-5 \mathrm{mg} \text { in an open pan } \\
-\beta=2-20^{\circ} \mathrm{C} / \mathrm{min} \\
\text { - Flow rate }=600 \mathrm{~mL} / \mathrm{min}\end{array}$ & $\begin{array}{l}\text { - Erucic: } \mathrm{E}_{\mathrm{a}}=89.6 \pm 4.4 ; \mathrm{A}=4.9 \times 10^{10} ; \mathrm{k}_{90^{\circ} \mathrm{C}}=0.006 \\
\text { - Oleic: } \mathrm{E}_{\mathrm{a}}=88.4 \pm 4.7 ; \mathrm{A}=1.0 \times 10^{11} ; \mathrm{k}_{90^{\circ} \mathrm{C}}=0.021 \\
\text { - Oleate: } \mathrm{E}_{\mathrm{a}}=95 \pm 4.7 ; \mathrm{A}=9.4 \times 10^{10} ; \mathrm{k}_{900^{\circ} \mathrm{C}}=0.002 \\
\text { - Trioleate: } \mathrm{E}_{\mathrm{a}}=91.8 \pm 13.3 ; \mathrm{A}=4.4 \times 10^{10} ; \mathrm{k}_{90^{\circ} \mathrm{C}}=0.002 \\
\text { - Linoleic: } \mathrm{E}_{\mathrm{a}}=72 \pm 2.9 ; \mathrm{A}=1.6 \times 10^{9} ; \mathrm{k}_{90^{\circ} \mathrm{C}}=0.071 \\
\text { - Linoleate: } \mathrm{E}_{\mathrm{a}}=76.4 \pm 5 ; \mathrm{A}=2.4 \times 10^{9} ; \mathrm{k}_{90^{\circ} \mathrm{C}}=0.024 \\
\text { - Trilinoleate: } \mathrm{E}_{\mathrm{a}}=74.3 \pm 3 ; \mathrm{A}=9.6 \times 10^{8} ; \mathrm{k}_{90^{\circ} \mathrm{C}}=0.020 \\
\text { - Linolenic: } \mathrm{E}_{\mathrm{a}}=62.4 \pm 3.7 ; \mathrm{A}=2.6 \times 10^{8} ; \mathrm{k}_{900^{\circ} \mathrm{C}}=0.027 \\
\text { - Linolenate: } \mathrm{E}_{\mathrm{a}}=74.5 \pm 8.2 ; \mathrm{A}=4.2 \times 10^{9} ; \mathrm{k}_{90^{\circ} \mathrm{C}}=0.082\end{array}$ & {$[63,64]$} \\
\hline $\begin{array}{l}\text { AMF with low, medium and } \\
\text { high CLA content }\end{array}$ & $\begin{array}{l}-100 \text { to } 350^{\circ} \mathrm{C} \\
-2 \mathrm{mg} \text { in an sealed pan } \\
-\beta=3,6,9,12 \text { and } 15^{\circ} \mathrm{C} / \mathrm{min} \\
\text { - Flow rate }=50 \mathrm{~mL} / \mathrm{min}\end{array}$ & $\begin{array}{l}\text { - Low CLA: } \mathrm{E}_{\mathrm{a}}=146.5 ; \mathrm{A}=4.1 \times 10^{14} ; \mathrm{k}_{200^{\circ} \mathrm{C}}=0.026 \\
\text { - Med CLA: } \mathrm{E}_{\mathrm{a}}=112.4 ; \mathrm{A}=3.6 \times 10^{10} ; \mathrm{k}_{200^{\circ} \mathrm{C}}=0.014 \\
\text { - High CLA: } \mathrm{E}_{\mathrm{a}}=87.6 ; \mathrm{A}=6.3 \times 10^{7} ; \mathrm{k}_{200^{\circ} \mathrm{C}}=0.013\end{array}$ & [9] \\
\hline $\begin{array}{l}\text { Cotton, corn, canola, safflower, } \\
\text { high oleic safflower, high }\end{array}$ & $\begin{array}{l}-1-1.5 \mathrm{mg} \text { in a sealed pan } \\
-\beta=1,5,10,15 \text { and } 20^{\circ} \mathrm{C} / \mathrm{min}\end{array}$ & $\begin{array}{l}\text { - Cotton: } \mathrm{E}_{\mathrm{a}}=63.3 ; \mathrm{A}=9.2 \times 10^{6} ; \mathrm{k}=0.37 \\
\text { - Corn: } \mathrm{E}_{\mathrm{a}}=77.7 ; \mathrm{A}=2.4 \times 10^{8} ; \mathrm{k}=0.43 \\
\end{array}$ & {$[7]$} \\
\hline
\end{tabular}




\begin{tabular}{|c|c|c|c|}
\hline Lipid & Experimental protocol & Kinetics parameters $\left(E_{a}, \mathrm{~kJ} / \mathrm{mol} ; A \min ^{-1} ; k, \min \right)$ & Ref \\
\hline $\begin{array}{l}\text { linoleic safflower, high oleic } \\
\text { sunflower, soybean and } \\
\text { sunflower }\end{array}$ & & $\begin{array}{l}\text { - Canola: } \mathrm{E}_{\mathrm{a}}=88.4 ; \mathrm{A}=7.6 \times 10^{9} ; \mathrm{k}=0.51 \\
\text { - Sufflower: } \mathrm{E}_{\mathrm{a}}=75.2 ; \mathrm{A}=1.8 \times 10^{8} ; \mathrm{k}=0.44 \\
\text { - High oleic sufflower: } \mathrm{E}_{\mathrm{a}}=88.7 ; \mathrm{A}=3.1 \times 10^{9} ; \mathrm{k}=0.48 \\
\text { - High linoleic sufflower: } \mathrm{E}_{\mathrm{a}}=73.5 ; \mathrm{A}=1.1 \times 10^{8} \mathrm{k}=0.42 \\
\text { - High oleic sunflower: } \mathrm{E}_{\mathrm{a}}=86.5 ; \mathrm{A}=1.8 \times 10^{9} ; \mathrm{k}=0.47 \\
\text { - Soybean: } \mathrm{E}_{\mathrm{a}}=79.6 ; \mathrm{A}=4.1 \times 10^{8} ; \mathrm{k}=0.44 \\
\text { - Sunflower: } \mathrm{E}_{\mathrm{a}}=63.8 ; \mathrm{A}=1.1 \times 10^{7} ; \mathrm{k}=0.38\end{array}$ & \\
\hline Base oil lubricants & $\begin{array}{l}-0.5 \mathrm{mg} \text { in a sealed pan } \\
-\beta=5,10 \text { and } 20^{\circ} \mathrm{C} / \mathrm{min} \\
\text { - Flow rate }=100 \mathrm{~mL} / \mathrm{min}\end{array}$ & $-\mathrm{E}_{\mathrm{a}}=13.8-83.9 \mathrm{~kJ} / \mathrm{mol} ; \mathrm{k}=0.11-0.75 \mathrm{~min}^{-1}$ & {$[25]$} \\
\hline $\begin{array}{l}\text { Rapeseed, soybean, sunflower, } \\
\text { lard and highly rancid oils }\end{array}$ & $\begin{array}{l}-100-360^{\circ} \mathrm{C} \\
-3-4 \mathrm{mg} \text { in an open pan } \\
-\beta=5-20^{\circ} \mathrm{C} / \mathrm{min} \\
-166 \mathrm{~mL} / \mathrm{min} \\
\text { - Antioxidants: BHT, BHA and PG }\end{array}$ & $\begin{array}{l}\text { - Rapeseed: } \mathrm{E}_{\mathrm{a}}=64-73 ; \mathrm{A}=7.4 \times 10^{5}-4.4 \times 10^{6} \\
\text { - Soybean: } \mathrm{E}_{\mathrm{a}}=62-64 ; \mathrm{A}=6.1 \times 10^{5}-7.1 \times 10^{5} \\
\text { - Sunflower: } \mathrm{E}_{\mathrm{a}}=60-62 ; \mathrm{A}=4.1 \times 10^{5}-6.6 \times 10^{5} \\
\text { - Lard: } \mathrm{E}_{\mathrm{a}}=92-93 ; \mathrm{A}=3.5 \times 10^{8}-2.7 \times 10^{8}\end{array}$ & {$[65]$} \\
\hline $\begin{array}{l}\text { Fat extracted from baby } \\
\text { formulas }\end{array}$ & $\begin{array}{l}-3-4 \mathrm{mg} \\
-\beta=4,6,7.5,10,12.5,15^{\circ} \mathrm{C} / \mathrm{min} \\
- \text { Flow rate }=50 \mathrm{~mL} / \mathrm{min}\end{array}$ & $-\mathrm{E}_{\mathrm{a}}=80-106, \mathrm{~A}=7.4 \times 10^{9}-1.1 \times 10^{-13} ; \mathrm{k}_{120^{\circ} \mathrm{C}}=0.079-0.122$ & {$[19]$} \\
\hline $\begin{array}{l}\text { High oleic sunflower (HOS) and } \\
\text { castor oil with blends of } \\
\text { antioxidants }\end{array}$ & $\begin{array}{l}\text { - } 100 \text { to } 250^{\circ} \mathrm{C} \\
-3-3.3 \mathrm{mg} \text { in an open pan } \\
-\beta=10^{\circ} \mathrm{C} / \mathrm{min} \\
\text { - Flow rate }=10 \mathrm{~mL} / \mathrm{min} \\
\text { - Antioxidants }(0.5-2 \mathrm{wt} \%): \mathrm{TOC}, \mathrm{PG} \text {, } \\
\text { AA and MBP }\end{array}$ & $\begin{array}{l}\text { - HOS: OOT }=191^{\circ} \mathrm{C} \\
\text { - HOS + PG: OOT }=225-233^{\circ} \mathrm{C} \\
\text { - HOS + AA: OOT }=206^{\circ} \mathrm{C} \\
\text { - HOS + TOC: OOT }=190-214^{\circ} \mathrm{C} \\
\text { - HOS + MBP: OOT }=226-242^{\circ} \mathrm{C} \\
\text { - Castor: OOT }=197{ }^{\circ} \mathrm{C} \\
\text { - Castor + PG: OOT }=233-242^{\circ} \mathrm{C} \\
\text { - Castor + AA: OOT }=208-212{ }^{\circ} \mathrm{C} \\
\text { - Castor + TOC: OOT }=195-203^{\circ} \mathrm{C} \\
\text { - Castor + MBP: OOT }=212-234^{\circ} \mathrm{C}\end{array}$ & {$[66]$} \\
\hline $\begin{array}{l}\text { Linolenic acid (LNA) with } \\
\text { different phenols }\end{array}$ & $\begin{array}{l}-50-300^{\circ} \mathrm{C} \\
-3-5 \mathrm{mg} \text { in an open pan } \\
-\beta=5,10,20,40,40 \text { and } 80^{\circ} \mathrm{C} / \mathrm{min} \\
\text { - Flow rate }=250 \mathrm{~mL} / \mathrm{min}\end{array}$ & $\begin{array}{l}- \text { LNA: } \mathrm{E}_{\mathrm{a}}=70.4 ; \mathrm{A}=5.6 \times 10^{9} \mathrm{~min}^{-1} ; \mathrm{k}_{90^{\circ} \mathrm{C}}=0.792 \\
-0.26 \mathrm{BHT} / \mathrm{LNA}: \mathrm{E}_{\mathrm{a}}=73 \pm 3.7 ; \mathrm{A}=8.9 \times 10^{9} ; \mathrm{k}_{90} \mathrm{C}=0.541 \\
-0.82 \mathrm{BHT} / \mathrm{LNA}: \mathrm{E}_{\mathrm{a}}=79.6 \pm 8.4 ; \mathrm{A}=2.4 \times 10^{10} ; \mathrm{k}_{90^{\circ} \mathrm{C}}=0.17 \\
-1.51 \text { BHT/LNA: } \mathrm{E}_{\mathrm{a}}=87 \pm 5.5 ; \mathrm{A}=2.0 \times 10^{11} ; \mathrm{k}_{90^{\circ} \mathrm{C}}=0.134 \\
-3.0 \text { BHT/LNA }: \mathrm{E}_{\mathrm{a}}=91.9 \pm 4.5 ; \mathrm{A}=6.5 \times 10^{11} ; \mathrm{k}_{90^{\circ} \mathrm{C}}=0.091 \\
-4.0 \text { BHT/LNA: } \mathrm{E}_{\mathrm{a}}=95.8 \pm 2.4 ; \mathrm{A}=2.1 \times 10^{12} ; \mathrm{k}_{90^{\circ} \mathrm{C}}=0.049\end{array}$ & {$[67]$} \\
\hline $\begin{array}{l}\text { LNA with BHT, olivetol and } \\
\text { DHZ }\end{array}$ & $\begin{array}{l}-50-350^{\circ} \mathrm{C} \\
-5 \mathrm{mg} \text { in an open pan } \\
-\beta=2-20^{\circ} \mathrm{C} / \mathrm{min} \\
\text { - Flow rate }=250 \mathrm{~mL} / \mathrm{min}\end{array}$ & $\begin{array}{l}- \text { LNA: } \mathrm{E}_{\mathrm{a}}=69.8 \pm 7.8 ; \mathrm{A}=2.2 \times 10^{9} \\
-1.2-11.6 \mathrm{BHT} / \mathrm{LNA}: \mathrm{E}_{\mathrm{a}}=82-141 \\
-1.1-8.2 \text { DHZ/LNA: } \mathrm{E}_{\mathrm{a}}=88-187 \\
-1.1-5.6 \text { Olivetal/LNA: } \mathrm{E}_{\mathrm{a}}=84-129\end{array}$ & {$[68]$} \\
\hline
\end{tabular}

Table 2. Summary of non-isothermal oxidation studies of lipids using differential scanning calorimetry

According to the Arrhenius principle, oil with a high $E_{a}$ value oxidizes faster at high temperatures, while oil with a low $E_{a}$ value oxidizes faster at low temperatures. Unfortunately, calculated values of $E_{a}$ should not be used as a single parameter to rank the oxidative stability of lipid systems. This was exemplified in blends of soybean/anhydrous milk fat [63] that were non-isothermally oxidized. Interestingly, as the percentage of unsaturated fatty acids increased, the onset temperature of oxidation decreased and the only kinetic parameter that exhibited the same pattern was the constant rate of oxidation. The calculated $E_{a}$ value is the cumulative effect of all the $E_{a}$ values available in the system during oxidation, including intermediate compounds that have their own kinetic values. An equation representing the overall activation energy for autoxidation of lipids was earlier proposed [54,56]. The overall effect included activation energies of initiation $\left(E_{i}\right)$, propagation $\left(E_{p}\right)$ and termination $\left(E_{t}\right)$ based on the classical rate equation for autoxidation of hydrocarbons.

Unfortunately, equation (10) has been applied to limited fatty acids $\left(\mathrm{C}_{12}-\mathrm{C}_{18}\right)[56,57]$ and correlations between other kinetic parameters and the initiation and termination activation energies are needed. 


$$
E=E_{p}+1 / 2 E_{i}-1 / 2 E_{t}
$$

The non-isothermal oxidation of different fatty acids and their esters [56, 57] showed that the calculated $E_{a}$ values are similar among the different tested samples, indicating that the oxidation does not occur on free or esterified carboxyl groups of fatty acids. The nonisothermal oxidation of anhydrous milk fat with different ratios of unsaturated/saturated fatty acids showed that the start temperature of oxidation shifted to lower values as the ratio increased [9]. More importantly, the kinetics parameters ( $E_{a}, A$ and $k$ ) calculated also decreased. The onset temperature of oxidation not only is affected by the amount of saturated fatty acids but also by the presence and abundance of aromatic compounds and their alkyl substitutions [7, 25]. Kinetic parameters obtained from different oils were compared with structural parameters obtained with NMR spectroscopy. Moreover, an increase in the methylene carbons of the fatty acid chains increased the oxidative stability while conjugated structures were rapidly oxidized.

The addition of antioxidants to enhance oxidative stability of oils can be evaluated using the DSC in non-isothermal mode. A novel approach based on DSC data, named protective factor $(\mathrm{PF})$ was provided in the literature [65]. In this investigation, the oxidation of methyl esters derived from rapeseed and waste frying oil was monitored at different concentrations of BHT and pyrogallol (PG). The oxidation onset temperature asymptotically increased with the addition of BHT and PG, without finding an optimum antioxidant concentration. In addition, the increase in the heating rate might change the reaction mechanisms in which antioxidants can capture free radicals, making difficult to compare their effectiveness. Therefore, the protective factor concept [65] was developed according to:

$$
\text { Protective factor }(P F)=\frac{\text { onset temperature of oil with antioxidant }}{\text { onset temperature of oil without antioxidant }}
$$

Values of PF lower than 1 means that the antioxidant has a pro-oxidant effect. On the other hand, PF values greater than one can be considered as a measurement of antioxidant effectiveness. Another important factor is the physical stability of the antioxidants. In a comparative study $[65,68]$, the addition of BHT, BHA and PG was evaluated in rapeseed, soybean, sunflower and lard oils. BHA and BHT were not effective antioxidants due to their volatility. These antioxidants escaped from the heated oil before they can react to neutralize free radicals. An optimum antioxidant concentration was found for BHT (8.4 mmol), BHA (2.8 mmol) and olivetol $(4.5 \mathrm{mmol})$ in oxidized linolenic acid [63-65]. After the optimal concentration, a decrease in the antioxidant activity was observed. Interestingly, at high temperatures $\left(<180^{\circ} \mathrm{C}\right)$, the antioxidants are no longer stable and their effectiveness significantly decreased. Similarly, $\alpha$-tocopherol and $L$-ascorbic acid 6-palmitate were not effective even at high concentrations (up to $2 \% \mathrm{wt}$ ) during the oxidation of either high oleic sunflower oil or castor oil [66, 69]. 


\subsection{Compensation theory}

A proper kinetic interpretation should include the compensation effect, which is usually used to explain whether the variations on effective activation energy values have physical meaning or they are caused by either variations of process conditions or complexity of the reaction systems. In previous investigations [69, 70], the compensation effect is illustrated for various thermal degraded materials, such as polymers, cellulosic materials and $\mathrm{CaCO}_{3}$. The compensation effect can be evaluated by plotting $\ln k$, obtained by equation (7), against $1 / T$. Figure 9 shows that an increase in the effective activation energy causes an increase in $l n$ $k$ (equation 7). Similarly, a decrease in the effective activation energy results in a lower value of $\ln k$. The point of concurrence, where the different lines intercept, corresponds to $\ln k_{\text {iso }}$ and $1 / T_{\text {iso }}$ ( $k_{\text {iso }}$ is the isokinetic rate constant and $T_{\text {iso }}$ is the isokinetic temperature), which indicates the existence of the compensation effect.
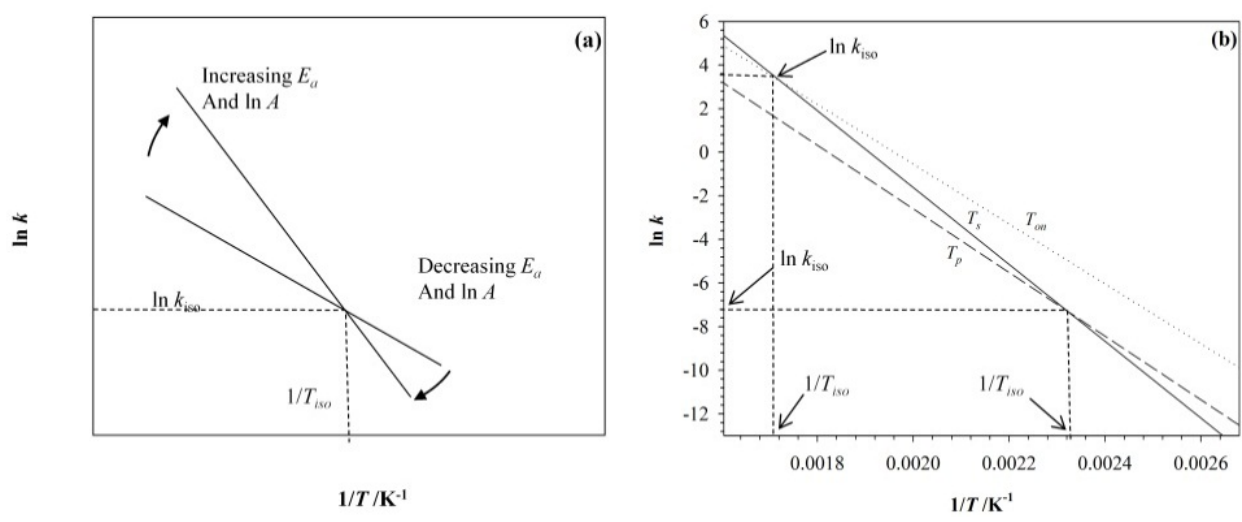

Figure 9. Arrhenius plot ( $\ln k v s$ 1/T) for the non-isothermal oxidation: (a) compensation effect theory adapted from reference [69], and (b) anhydrous milk fat [9].

In studies of non-isothermal oxidation of anhydrous milk fat (AMF) [9], there is no concurrence at a single point. Therefore, the non-isothermal oxidation of AMF does not exhibit a compensation effect and thus the variations in kinetic parameters have no physical background. In fact, AMF is a very complex fat mainly composed of triacylglycerols that have a glycerol backbone to which three fatty acid moieties are esterified. These triacylglycerols are extremely diverse in chain lengths, position and number of unsaturations of their fatty acids [72]. Moreover, more than 400 fatty acids in milk fat were found [73]. Therefore, several reactions with different constant rates simultaneously occur and DSC only detects those reactions that have the greatest exothermal effect. This could explain why the variations in effective activation energy values have no physical meaning or there is no compensation effect.

The isokinetic temperature can also be defined as the temperature at which two rate constants of two different reactions are equal. For a set of kinetic parameters of two different reactions, the isokinetic temperature can be expressed as: 


$$
A_{1} \cdot \exp \left(\frac{-E_{1}}{R \cdot T_{i s o}}\right)=A_{2} \cdot \exp \left(\frac{-E_{2}}{R \cdot T_{i s o}}\right)
$$

The isokinetic temperature of autoxidation of lecithin and linolenic acid calculated using equation (12) was $167^{\circ} \mathrm{C}$ [57]. This observation exemplifies the difficulty in determining the oxidative stability of multicomponent systems. For example, if the oxidation test is conducted at a temperature below $T_{\text {iso, }}$ linolenic acid oxidizes faster than lecithin. But, if the same test is conducted at a temperature equal to $\mathrm{T}_{\text {iso, }}$ both lipids have the same oxidative stability. Contrary, lecithin oxidizes faster than linolenic acid above Tiso. Consequently, the estimation of the oxidative stability based only on the onset temperature is misleading. Therefore, interpretation of the shape of non-isothermal oxidation curves in combination with kinetic parameters can provide a better interpretation of the oxidative behavior in multicomponent systems.

\section{Case studies of lipid oxidation after processing using new technologies}

\subsection{Kinetics of non-isothermal oxidation of anhydrous milk fat (AMF) rich in conjugated linoleic acid (CLA) after hydrolysis}

AMF is the richest source of CLA composed of geometrical and positional isomers of linoleic acid. CLA has potential benefits, such as cancer prevention, atherosclerosis, weight control, and bone formation [74]. Additionally, CLA concentration in milk can be markedly enhanced through diet manipulation and nutritional management of dairy cattle [75]. In CLA-enriched AMF, CLA is distributed throughout different triacylglycerols together with other fatty acids, limiting its applicability as ingredient in different milk fat-based products. One known approach to produce free fatty acids (FFA) is through enzymatic hydrolysis. The enzymatic hydrolysis of AMF rich in CLA yielded around 88\% of free fatty acids (FFA) [76, 77]. Unfortunately, FFAs are more susceptible to oxidation than those fatty acids attached to the triacylglycerol backbone.

Figure 10 shows the DSC curves of non-hydrolyzed and hydrolyzed AMF rich in CLA. Although the DSC curves were quite different between non-hydrolyzed AMF (blue and black lines) and hydrolyzed AMF (green and red lines), the maximum peak temperatures were in the same range. This observation supports the hypothesis that changes in the DSC signal below the temperature of the first peak can be attributed to oxidation and changes in DSC signal above $\mathrm{TP}$ correspond to thermal decomposition and advanced oxidation products as shown in Figure 8. Figure 10 also shows that the oxidation of hydrolyzed AMF starts at low temperatures $\left(\sim 108^{\circ} \mathrm{C}\right)$, making difficult to obtain a consistent baseline. Therefore, the kinetic parameters were calculated using the onset temperature obtained as described in Section 5.1.

Table 3 shows the onset oxidation temperature and kinetic parameters of non-hydrolyzed and enzymatic hydrolyzed AMF rich in CLA. As expected, the $E_{a}$ for the hydrolyzed fat is greater than that obtained for the non-hydrolyzed fat. Interestingly, the constant reaction 


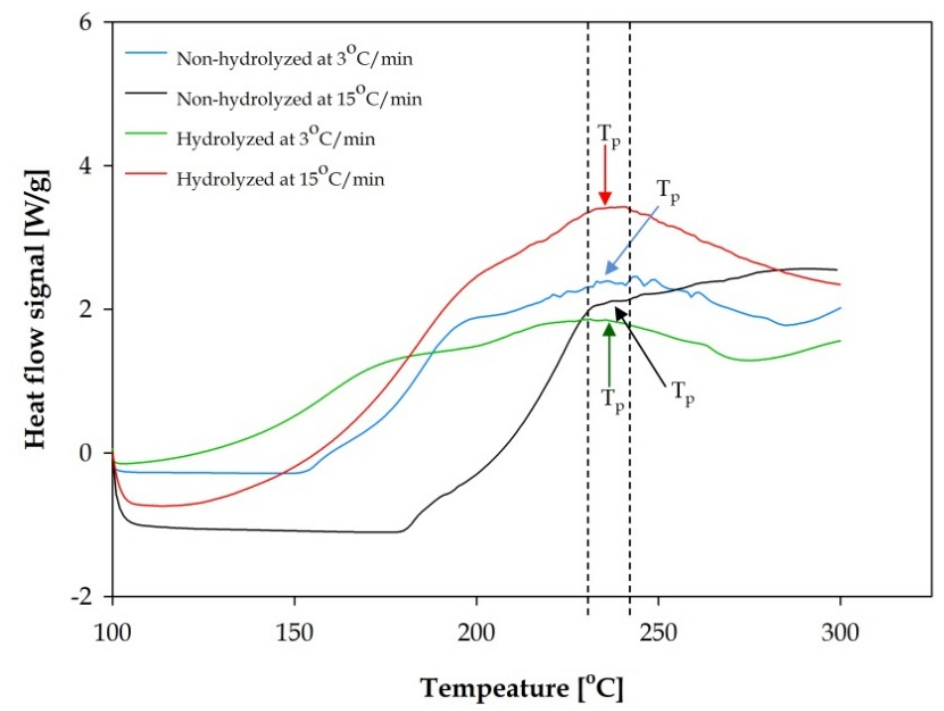

Figure 10. Non-isothermal oxidation of non-hydrolyzed and hydrolyzed anhydrous milk fat rich in CLA. $T_{p}$ - maximum heat flow temperature.

\begin{tabular}{ccc}
\hline Heating rate $\left[{ }^{\circ} \mathbf{C} / \mathbf{m i n}\right]$ & Non-hydrolyzed AMF $\left[{ }^{\circ} \mathrm{C}\right]$ & Hydrolyzed AMF $\left[{ }^{\circ} \mathbf{C}\right]$ \\
\hline 3 & $173.47 \pm 0.1$ & $125.06 \pm 1.4$ \\
6 & $184.71 \pm 2.3$ & $132.46 \pm 0.3$ \\
9 & $192.13 \pm 0.7$ & $133.25 \pm 1.2$ \\
12 & $197.85 \pm 3.7$ & $132.46 \pm 0.3$ \\
15 & $198.66 \pm 0.3$ & $136.78 \pm 0.1$ \\
\hline$E a[\mathrm{~kJ} / \mathrm{mol}]$ & 82.42 & 175.78 \\
$A\left[\mathrm{~min}^{-1}\right]$ & $8.7 \times 10^{7}$ & $2.3 \times 10^{20}$ \\
$k_{130^{\circ} \mathrm{C}}[\mathrm{min}]$ & 0.002 & 0.003 \\
$k_{200^{\circ} \mathrm{C}}[\mathrm{min}]$ & 0.075 & 10.28 \\
\hline
\end{tabular}

Table 3. Onset temperature of oxidation for anhydrous milk fat (AMF)

rates $(k)$ calculated at $130{ }^{\circ} \mathrm{C}$ were similar for the non-hydrolyzed and hydrolyzed samples. However, the constant rate of hydrolyzed fat was dramatically higher than that of nonhydrolyzed fat at $200^{\circ} \mathrm{C}$.

The isokinetic temperatures of these two fats were calculated mathematically and graphically using equation (12) and Arrhenius plot, respectively. Figure 11 shows the compensation effect for the oxidation of non-hydrolyzed and hydrolyzed AMF rich in CLA. From this figure, the $T_{\text {iso }}$ and $k_{\text {iso }}$ were obtained $\left(T_{\text {iso }}=120^{\circ} \mathrm{C}\right.$ and $\left.k_{\text {iso }}=0.0011 \mathrm{~min}\right)$. Similarly, the $T_{\text {iso }}$ and $k_{\text {iso }}$ calculated mathematically with equation (12) were $118^{\circ} \mathrm{C}$ and $0.0010 \mathrm{~min}$, respectively. However, $T_{i s o}$ for non-hydrolyzed AMF is unrealistic since the start temperature of oxidation is around $155^{\circ} \mathrm{C}$. Therefore, oxidation of either non-hydrolyzed or hydrolyzed AMF rich in CLA does not exhibit a compensation effect. 


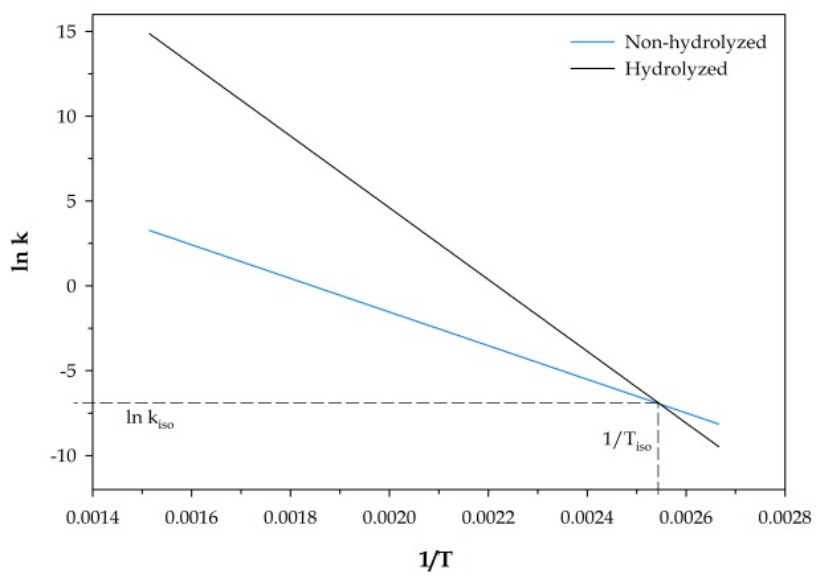

Figure 11. Arrhenius plot for the non-isothermal oxidation of non-hydrolyzed and hydrolyzed anhydrous milk fat rich in CLA.

\subsection{Oxidative stability of AMF rich in CLA treated with pressure assisted thermal processing}

CLA is not stable upon thermal processing and significant losses of its biological activity occurred through oxidation [78]. The application of high pressure (100-600 MPa) to a preheated sample can preserve the biological activity of functional compounds [79]. This is because the rise in temperature due to adiabatic heating is used to reach the target temperature, reducing the thermal damage due to the lack of temperature uniformity that occurs in traditional thermal processes [80, 81]. This technology is known as pressureassisted thermal processing (PATP). Pressure alters interatomic distance, acting mainly on those weak interactions which bond energy is distance-dependent, such as van der Waals forces, electrostatic forces, hydrogen bonding and hydrophobic interactions of proteins. Based on the distance dependence, any pressurized sample would have its covalent bonds intact. This has been the central hypothesis in preserving the biological activity of functional compounds, such as ascorbic acid, folates, vitamins and anthocyanins [82-85].

The effects of PATP conditions on the antiradical ability of CLA in AMF were reported [86]. CLA can donate hydrogen to form a CLA-free radical that further reacts to inhibit hydroperoxides formation, depending on the final CLA retention. This suggests that the retained CLA after PATP treatment might enhance the oxidative stability of AMF. After PATP treatments, samples of AMF rich in CLA were oxidized at $6^{\circ} \mathrm{C} / \mathrm{min}$ to calculate the start temperature of oxidation using the method described earlier in Section 5.1 of this chapter.

Figure 12 shows the influence of the retained CLA on the start temperature of oxidation $\left(\mathrm{T}_{\mathrm{s}}\right)$. The stability of AMF is influenced in a non-linear mode by the CLA retention. Values of the 
start temperature of oxidation $\left(\sim 165-155^{\circ} \mathrm{C}\right)$ were obtained when the CLA retention was between 85 to $100 \%$. On the other hand, the lowest value of the start temperature of oxidation $\left(141^{\circ} \mathrm{C}\right)$ was obtained at $40 \%$ of CLA retention.

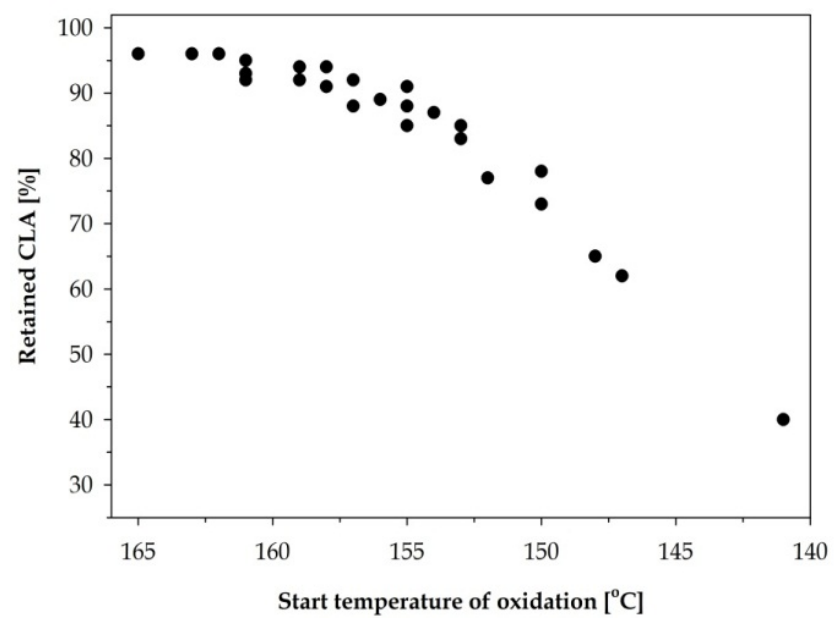

Figure 12. Influence of CLA retention on the start temperature $\left(T_{s}\right)$ of oxidation in anhydrous milk fat rich in CLA.

A possible reason for the CLA-Ts relationship is that CLA can act as an antioxidant capturing those free radicals responsible for the lipid oxidation. This antioxidant behavior was clearly demonstrated in an earlier study by inducing lipid oxidation of fish oil by adding tert-butyl hydroperoxide. CLA effectively reduces lipid peroxidation as measured by chemiluminescence [86]. In addition, the antiradical or scavenging ability of CLA isomers measured by DPPH (2,2-diphenyl-1-picryl-hydrazyl-hydrate) technique depended on the CLA concentration [87].

\section{Conclusions}

The use of DSC to analyse lipid oxidation is a reliable, simple and convenient technique. It provides qualitative and quantitative information and offers unique advantages, such as the small amount of sample use, short test time, and good reproducibility. Additionally, the effectiveness of a particular antioxidant can be evaluated using DSC, measuring changes in the oxidation onset times or temperatures. The data obtained from DSC lipid oxidation have been extensively studied and correlated with other oxidation methods, such as the Rancimat method, PV, spectrophotometric and GC analysis of fats and oils from various sources.

A proper interpretation of DSC oxidation experiments should include sample composition, kinetic parameters $\left(E_{a}, A\right.$, and $\left.k\right)$ in combination with the compensation theory. In 
multicomponent systems, the fat sometimes needs to be extracted from the matrix. Therefore, the lipid oxidative behaviour might be different from its original matrix. The results obtained from DSC oxidation depend upon the conditions used to prepare the sample and the heating protocol used. Factors, such as degree of saturation, amount of free fatty acids, chain length and the presence of natural antioxidants influence the oxidative stability and kinetic parameters. DSC can be coupled with other analytical techniques, such as GC, NMR, HPLC, etc, to provide a better description of the oxidative stability of fats and oils.

\section{Author details}

M.D.A. Saldaña and S.I. Martínez-Monteagudo

Department of Agricultural, Food and Nutritional Science, University of Alberta, Edmonton, AB, Canada

\section{Acknowledgement}

The authors thank to Alberta Livestock and Meat Agency Ltd. (ALMA) and to the Natural Sciences and Engineering Research Council of Canada (NSERC) for funding this project. Martinez-Monteagudo expresses his gratitude to Consejo Nacional de Ciencia y Tecnologia (CONACYT, Mexico) and Instituto de Inovacion y Transferencia Tecnologica ( $\mathrm{I}^{2} \mathrm{~T}^{2}$, Mexico) for the financial support (nr 187497).

\section{References}

[1] Kamal-Eldin A, Pokorn J (2005) Lipid oxidation products and methods used for their analysis. In Kamal-Eldin A, Pokorny J, editors. Analysis of lipid oxidation. AOCS Publishing, eBook ISBN: 978-1-4398-2239-5.

[2] O'Connor, TP, O'Brien NM (2006) Lipid oxidation. In Fox, PF, McSweeney P, editors. Advanced Dairy Chemistry, Volume 2: Lipids (3 ${ }^{\text {rd }}$ Edition). Springer-Verlag. pp. 557600 .

[3] Gray JI (1978) Measurement of lipid oxidation: A review. J. Am. Oil Chem. Soc. 55:539546.

[4] Bradley DG, Min DB (1992) Singlet oxygen of foods. Crit. Rev. Food Sci. Nutr. 31:211236.

[5] Shahidi F, Zhong Y (2010) Lipid oxidation and improving the oxidative stability. Chem. Soc. Rev. 39:4067-4079.

[6] Labuza TP (1971) Kinetics of lipid oxidation. Crit. Rev. Food Technol. 2:355-404.

[7] Adhvaryu A, Erhan SZ, Perez JM (2000) Oxidation kinetic studies of oils derived from unmodified and genetically modified vegetables using pressurized differential scanning calorimetry and nuclear magnetic resonance spectroscopy. Thermochim. Acta. 364: 9797. 
[8] Privett,OS, Blank ML (1962) Initial stages of autoxidation. J. Am. Oil Chem. Soc. 39: 465468.

[9] Martínez-Monteagudo SI, Saldaña MDA, Kennelly JJ (2012) Kinetics of non-isothermal oxidation of anhydrous milk fat rich conjugated linoleic acid using differential scanning calorimetry. J. Therm. Anal. Calorim. 107: 973-981.

[10] Choe E, Min DB (2006) Chemistry and reactions of reactive oxygen species in foods. Crit. Rev. Food Sci. 46: 1-22.

[11] Brimberg UI, Kamal-Eldin A (2003) On the kinetics of the autoxidation of fats substrates with conjugated double bonds. Eur. J. Lipid Sci. Tech. 105: 17-22.

[12] Hamalainen TI, Sundberg S, Makkinen M, Hase T, Hopia A (2001) Hydroperoxide formation during autoxidation of conjugated linoleic acid methyl ester. Eur. J. Lipid Sci. Tech. 103: 588-593.

[13] Kenar JA, Gunstone FD, Knothe G (2007) Chapter 8: Chemical properties. In Harwood JL, Frank D, Gunstone FD, Dijkstra AJ, editors. The lipid handbook ( $3^{\text {rd }}$ Edition). CRC Press. pp. 535-590.

[14] Lopez C, Lavigne F, Lesieur P, Bourgaux C, Ollivon M (2001) Thermal and structural behavior of milk fat. 1. Unstable species of anhydrous milk fat. J. Dairy Sci. 84: 756-766.

[15] Jensen RG (2002) The composition of bovine milk lipids: January 1995 to December 2000. J. Dairy Sci. 85: 295-300.

[16] Pokorny J (2005) Volumetric analysis of oxidized lipids. In Kamal-Eldin A, Pokorny J, editors. Analysis of lipid oxidation. AOCS Publishing.

[17] Simon P (2006) Induction periods theory and applications. J. Therm. Anal. Calorim. 84: 263-270.

[18] Fasina OO, Craig-Schmidt M, Colley Z, Hallman H (2008) Predicting melting characteristics of vegetable oils from fatty acid composition. LWT - Food Sci. Technol. 41: 1501-1505.

[19] Wirkowska M, Ostrowska-Ligeza E, Gorska A, Koczon P (2012) Thermal properties of fats extracted from powdered baby formulas. J. Therm. Anal. Calorim. 110:137-143

[20] Kousksou T, Jamil A, Zeraouli Y, Dumas JP (2006) DSC study and computer modelling of the melting process in ice slurry. Thermochim. Acta. 448: 123-129.

[21] Castello ML, Dweck J, Aranda DAG (2011) Kinetic study of thermal processing of glycerol by thermogravimetry. J. Therm. Anal. Calorim. 105:737-746

[22] Roy S, Riga AT, Alexander KS (2002) Experimental design aids the development of differential scanning calorimetry standard test procedure for pharmaceuticals. Thermochim. Acta. 392-393:399-404.

[23] ISO 11357-6:2008 (E) Plastics - differential scanning calorimetry (DSC) - Part 6: Determination of oxidation induction time (isothermal OIT) and oxidation induction temperature (dynamic OIT).

[24] Tsang W, Walker JA (1985) Characterization of RDF properties through high pressure differential scanning calorimetry. Resour Conserv. 9:355-365. 
[25] Adhvaryu A, Perez JM, Singh ID (1999) Application of quantitative NMR spectroscopy to oxidation kinetics of base oils using pressurized differential scanning calorimetry technique. Energ Fuels. 13:493-498.

[26] Butrow AB, Seyler RJ (2003) Vapor pressure by DSC: extending ASTM E 1782 below 5 kPa. Thermochim. Acta. 402:145-152.

[27] Kousksou T, Jamil A, El-Omari K, Zeraouli Y, Le Guer Y (2011) Effect of heating rate and simple geometry on the apparent specific heat capacity: DSC applications. Themochim. Acta. 519:59-64.

[28] Litwinienko G, Daniluk A, Kasprzycka-Guttman T (2000) Study on autoxidation kinetics of fats by differential scanning calorimetry. 1 . Saturated $\mathrm{C}_{12}-\mathrm{C}_{18}$ fatty acids and their esters. Ind. Eng. Chem. Res. 39:1.12.

[29] Vyazovkin S, Wight CA (1997) Kinetics in solids. Annu. Rev. Phys. Chem. 48:125-149.

[30] Bouzidi L, Boodhoo M, Humphrey KL, Narine SS (2005) Use of the first and second derivatives to accurately determine key parameters of DSC thermographs in lipid crystallization studies. Thermochim. Acta. 439:94-102.

[31] Šimon P (2007) The single-step approximation attributes, strong and weak sides. J. Therm. Anal. Calorim. 88:709-715.

[32] Vyazovkin S, Wight CA (1999) Model-free and model-fitting approaches to kinetic analysis of isothermal and non-isothermal data. Thermochim. Acta. 341:53-68.

[33] Šimon P, Kolman L, Niklova I, Schmidt S (2000) Analysis of the induction period of oxidation of edible oils by differential scanning calorimetry. J. Am. Oil Chem. Soc. 77:639-642.

[34] Šimon P, Kolman L (2001) DSC study of oxidation induction periods. J. Therm. Anal. Calorim. 64:813-820.

[35] Schmid M, Ritter A, Affolter S (2006) Determination of oxidation induction time and temperature by DSC. J. Therm. Anal. Calorim. 2:367-371.

[36] Šimon P, Thomas PS, Okuliar J, Ray AS (2003) An incremental integral isoconversional method determination of activation parameters. J. Therm. Anal. Calorim. 72:867-874.

[37] Šimon P, Hynek D, Malikova M, Cibulkova Z (2008) Extrapolation of accelerated thermooxidative tests to lower temperatures applying non-Arrhenius temperature functions. J. Them. Anal. Calorim. 3:817-821.

[38] Šimon P (2009) Material stability predictions applying a new non-Arrhenian temperature function. J. Therm. Anal. Calorim. 2:391-396.

[39] Schmid M, Affolter S (2003) Interlaboratory tests on polymers by differential scanning calorimetry (DSC): determination and comparison of oxidation induction time (OIT) and oxidation induction temperature (OIT*). Polym. Test. 22:419-428.

[40] Cross CK (1970) Oil stability: A DSC alternative for the active oxygen method. J. Amer. Oil Chem. Soc. 47:229-230.

[41] Yamazaki M, Nagao A, Komomiya K (1980) High pressure differential thermal analysis of fatty acid methyl esters and triglycerides. J. Amer. Oil Chem. Soc. 57:59-60. 
[42] Raemy A, Froelicher I, Loeliger J (1987) Oxidation of lipids studied by isothermal heat flux calorimetry. Thermochim. Acta. 114:159-164.

[43] Arain S, Sherazi STH, Bhanger MI, Talpur FN, Mahesar SA (2009) Oxidative stability assessment of Bauhinia purpurea seed oil in comparison to tow conventional vegetable oils by differential scanning calorimetry and Rancimat methods. Thermochim. Acta. 484:1-3.

[44] Pardauil JJR, Souza LKC, Molfetta F, Zamian JR, Filho GNR, da Costa CEF (2011) Determination of the oxidative stability by DSC of vegetable oils from the Amazonian area. Bioresource Technol. 102:5873-5877.

[45] Gromodzka J, Wardencki W, Pawlowicz R, Muszyn G (2010) Photoinduced and thermal oxidation of rapeseed and sunflower oils. Eur. J. Lipid Sci. Tech. 112:1229-1235.

[46] Velasco J, Adersen ML, Skibsted LH (2004) Evaluation of oxidative stability of vegetable oils by monitoring the tendency to radical formation. A comparison of electron spin resonance spectroscopy with the Rancimat method and differential scanning calorimetry. Food Chem. 85:623-632.

[47] Kowalski B (1989) Determination of oxidative stability of edible vegetable oils by pressure differential scanning calorimetry. Thermochim. Acta. 156:347-358.

[48] Kowalski B, Ratusz K, Miciula A, Krygier K (1997) Monitoring of rapeseed oil autoxidation with a pressure differential scanning calorimeter. Themochim. Acta. 307:177-121.

[49] Rudnik E, Szczucinska A, Gwardiak H, Szulc A, Winiarska A (2001) Comparative studies of oxidative stability of linseed oil. Thermochim. Acta. 370:135-140.

[50] Kowaslki B, Ratusz K, Kowalska D, Bekas W (2004) Determination of the oxidative stability of vegetable oils by differential scanning calorimetry and Rancimat measurements. Eur. J. Lipid Sci. Tech. 106:165-169.

[51] Tan CP, Che Man YB, Selamat J, Yusoff MSA (2001) Application of Arrhenius kinetics to evaluate oxidative stability in vegetable oils by isothermal differential scanning calorimetry. J. Am. Oil Chem. Soc. 78:1133-1138.

[52] Tan CP, Che Man YB, Selamat J, Yusoff MSA (2002) Comparative studies of oxidative stability of edible oils by differential scanning calorimetry and oxidative stability index methods. Food Chem. 76:385-389.

[53] Litwinienko G, Kasprzycka-Guttman, Jarosz-Jarszewska M (1995) Dynamic and isothermal DSC investigation of the kinetic of thermooxidative decomposition of some edible oils. J. Therm. Anal. 45:741-750.

[54] Litwinienki G, Daniluka A, Kasprzycka-guttman T (1999) A differential scanning calorimetry study on the oxidation of $\mathrm{C}_{12}-\mathrm{C}_{18}$ saturated fatty acids and their esters. J. Am. Oil Chem. Soc. 76:655-657.

[55] Cifti ON, Kowalski B, Gogus F, Fadiloglu S (2009) Effect of the addition of a cocoa butter-like fat enzymatically produced from olive pomace oil on the oxidative stability of cocoa butter. J. Food Sci. 4:E184-E190. 
[56] Litwinienko G (2001) Autoxidation of unsaturated fatty acids and their esters. J. Therm. Anal. Calorim. 65:639-646.

[57] Litwinienko G, Kasprzycka-Guttman T, Studzinski M (1997) Effects of selected phenol derivatives on the autoxidation of linolenic acid investigated by DSC non-isothermal methods. Thermochim. Acta. 307:97-106.

[58] Ulkowski M, Musialik M, Litwinienko G (2005) Use of differential scanning calorimetry to study lipid oxidation. 1. Oxidative stability of lecithin and linolenic acid. J. Agric. Food. Chem. 53:9073-9077.

[59] Litwinienko G, Kasprzycka-Guttman T (1998) A DSC study on thermoxidation kinetics of mustard oil. Thermochim. Acta. 319:185-191.

[60] Ostrowska-Ligeza E, Bekas W, Kowalska D, Lobacz M, Wroniak M, Kowalski B (2010) Kinetics of commercial olive oil oxidation: Dynamic differential scanning calorimetry and Rancimat studies. Eur. J. Lipid Sci. Tech. 112:268-274.

[61] Jimenez-Marquez J, Beltran-Maza G (2003) Aplicación de la calorimetría diferencial de barrido (CDB) en la caracterización del aceite de oliva virgen. Grasas Aceites. 54:403409.

[62] Vittadini E, Lee JH, Frega NG, Min DB, Vodovotz Y (2003) DSC determination of thermally oxidized olive oil. J. Am. Oil Chem. Soc. 8:533-537.

[63] Thurgood J, Ward R, Martini S (2007) Oxidation kinetics of soybean oil/anhydrous milk fat blends: A differential scanning calorimetry study. Food Res. Int. 40:1030-1037.

[64] Litwinienko G, Kasprzycka-Guttman T (2000) Study on the autoxidation kinetics of fat components by differential scanning calorimetry. 2 . Unsaturated fatty acids and their esters. Ind. Eng. Chem. Res. 39:13-17.

[65] Polavka J, Paligova J, Cvengroš J, Šimon P (2005) Oxidation stability of methyl esters studied by differential thermal analysis and Rancimat. J. Am. Oil Chem. Soc. 82:519-524.

[66] Quinchia LA, Delgado MA, Valencia C, Franco JM, Gallegos C (2011) Natural and synthetic antioxidant additives for improving the performance of new biolubricant formulations. J. Agr. Food Chem. 59:12917-12924.

[67] Kowalski B (1991) Thermal-oxidative decomposition of edible oils and fats. DSC stidies. Thermochim. Acta. 184:49-57.

[68] Musialik M, Litwinienko G (2007) DSC study of linolenic acid autoxidation inhibited by BHT, dehydrozingerone and olivetol. J. Therm. Anal. Calorim. 88:781-785.

[69] Agrawal RK (1989) The compensation effect - a fact or a fiction. J. Therm. Anal. 35:909917.

[70] Agrawal RK (1986) On the compensation effect. J. Therm. Anal. 31:73-86.

[71] Lopez C, Lavigne F, Lesieur P, Bourgaux C, Ollivon M (2001) Thermal and structural behavior of milk fat. 1. Unstable species of anhydrous milk fat. J. Dairy Sci. 84:756-766.

[72] Jensen RG (2002) The composition of bovine milk lipids: January 1995 to December 2000. J. Dairy Sci. 85:295-300. 
[73] Lock AL, Bauman DE (2004) Modifying milk fat composition of dairy cows to enhance fatty acids beneficial to human health. Lipids. 39:1197-1206.

[74] Bell JA, Griinari JM, Kennelly JJ (2006) Effect of safflower oil, flaxseed oil, monensin, and vitamin $\mathrm{E}$ on concentration of conjugated linoleic acid in bovine milk fat. J. Dairy Sci. 89:733-748.

[75] Martinez-Monteagudo SI, Khan M, Saldaña MDA, Temelli F (2011) Obtaining a milk fraction rich in conjugated linoleic acid. Abstract 45, In $24^{\text {th }}$ Canadian Conference on Fats and Oils, September 26-27th, Edmonton, AB, Canada.

[76] Prado GHC, Khan M, Saldaña MDA, Temelli F (2012) Enzymatic hydrolysis of conjugated linoleic acid-enriched anhydrous milk fat in supercritical carbon dioxide. J. Supercrit. Fluids. 66:198-206.

[77] Campbell W, Drake MA, Larick DK (2003) The impact of fortification with conjugated linoleic acid (CLA) on the quality of fluid milk. J. Dairy Sci. 86:43-51.

[78] Mathys A, Reineke K, Heinz V, Knorr D (2009) High pressure thermal sterilization development and application of temperature controlled spore inactivation studies. High Pressure Res. 29:3-7.

[79] Knoerzer K, Buckow R, Versteeg C (2010) Adiabatic compression heating coefficients for high-pressure processing - a study of some insulating polymer materials. J. Food Eng. 98:110-119.

[80] Wilson DR, Dabrowski L, Stringer S, Moezelaar R, Brocklehurst TF (2008) High pressure in combination with elevated temperature as a method for the sterilization of food. Trends Food Sci. Tech. 19:289-299.

[81] Oley I, Verlinde P, Hendrickx M, Van Loey A (2006) Temperature and pressure stability of L-ascorbic acid and/or [6s] 5-methyltetrahydrofolic acid: A kinetic study. Eur. Food Res. Tech. 223:71-77.

[82] Butz P, Serfert Y, Fernandez-Garcia A, Dieterich S, Lindauer R, Bognar A, Tauscher B (2004) Influence of high-pressure treatment at $25^{\circ} \mathrm{C}$ and $80^{\circ} \mathrm{C}$ on folates in orange juice and model media. J. Food Sci. 69:117-121.

[83] Matser AA, Krebbers B, van den Berg RW, Bartels PV (2004) Advantages of high pressure sterilisation on quality of food products. Trends Food Sci. Tech. 15:79-85.

[84] Verbeyst L, Oey I, Van der Plancken I, Hendrickx M, Van Loey A (2010) Kinetic study on the thermal and pressure degradation of anthocyanins in strawberries. Food Chem. 123:269-274.

[85] Martinez-Monteagudo SI, Saldaña MDA, Torres JA, Kennelly JJ. (2012). Effect of pressure-assisted thermal sterilization on conjugated linoleic acid (CLA) content in CLA-enriched milk, Innov Food Sci Emerg Technol, doi 10.1016/j.ifset.2012.07.004.

[86] Martinez-Monteagudo SI, Saldaña MDA (2011) Changes in conjugated linoleic acid (CLA) and antiradical ability of anhydrous milk fat treated with pressure assisted thermal sterilization. Abstract 43, In $24^{\text {th }}$ Canadian Conference on Fats and Oils, September 26-27th, Edmonton, AB, Canada. 
Applications of Calorimetry in a Wide Context -

474 Differential Scanning Calorimetry, Isothermal Titration Calorimetry and Microcalorimetry

[87] Fagali N, Catala A (2008) Antioxidant activity of conjugated acid isomers, linoleic acid and its methyl ester determined by photoemission and DPPH techniques. Biophys. Chem. 137:56-62. 